\title{
1 Models for estimating daily rainfall erosivity in China
}

2 Yun XIE ${ }^{\mathrm{a}, \mathrm{b}}$, Shui-qing YIN ${ }^{\mathrm{a}, \mathrm{b} *}$, Bao-yuan LIU $^{\mathrm{a}, \mathrm{b}}$, Mark A. NEARING $^{\mathrm{c}}$, Ying ZHAO $^{\mathrm{a}, \mathrm{b}}$

$3 \quad{ }^{a}$ State Key Laboratory of Earth Surface Processes and Resource Ecology, Beijing Normal

4 University, Beijing 100875, China

$5 \quad{ }^{b}$ School of Geography, Beijing Normal University, Beijing 100875, China

${ }^{c}$ USDA-ARS Southwest Watershed Research Center, Tucson 85719, U.S.A.

* Corresponding author: Shui-qing Yin, Xin-Jie-Kou-Wai Street, Haidian district, Beijing, China, 100875. Phone: 0086-10-58807455-1687; Email: yinshuiqing@bnu.edu.cn.

Abstract: maximum 30 minutes intensity by event $\left(\mathrm{EI}_{30}\right)$ and year. This rainfall erosivity index is widely used for empirical soil loss prediction. Its calculation, however, requires high temporal resolution rainfall data that are not readily available in many parts of the world. The purpose of this study was to parameterize models suitable for estimating erosivity from daily rainfall data, which are more widely available. One-minute resolution rainfall data recorded in sixteen stations over the eastern water erosion impacted regions of China were analyzed. The R-factor ranged from 781.9 to $8258.5 \mathrm{MJ} \mathrm{mm} \mathrm{ha}^{-1} \mathrm{~h}^{-1} \mathrm{y}^{-1}$. A total of 5942 erosive events from one-minute resolution rainfall data of ten stations were used to parameterize three models, and 4949 erosive events from the other six stations were used for validation. A threshold of daily rainfall between days classified as erosive and non-erosive was suggested to be $9.7 \mathrm{~mm}$ based on these data. Two of the models (I and II) used power law functions that required only daily rainfall totals. Model I used different model coefficients in the cool season (Oct.-Apr..) and warm season (May-Sept.), and Model II was fitted with a sinusoidal

\footnotetext{
* Corresponding author. Tel: +86-10-58807455-1687; Fax: +86-10-58806955. E-mail: yinshuiqing@bnu.edu.cn
} 
curve of seasonal variation. Both Model I and Model II estimated the erosivity index for average annual, yearly, and half-month temporal scales reasonably well, with the symmetric mean absolute percentage error $\mathrm{MAPE}_{\mathrm{sym}}$ ranging from $10.8 \%$ to $32.1 \%$. Model II predicted slightly better than Model I. However, the prediction efficiency for the daily erosivity index was limited, with the symmetric mean absolute percentage error being 68.0\% (Model I) and 65.7\% (Model II) and Nash-Sutcliffe model efficiency being 0.55 (Model I) and 0.57 (Model II). Model III, which used the combination of daily rainfall amount and daily maximum 60-min rainfall, improved predictions significantly, and produced a Nash-Sutcliffe model efficiency for daily erosivity index prediction of 0.93 . Thus daily rainfall data was generally sufficient for estimating annual average, yearly, and half-monthly time scales, while sub-daily data was needed when estimating daily erosivity values.

Keywords: Soil erosion; rainfall erosivity; daily rainfall; USLE; China

\section{Introduction}

The Universal Soil Loss Equation (USLE) and its revised versions (RUSLE, RULSE2) are the most widely used models for predicting soil erosion on agricultural fields (Wischmeier and Smith, 1965; Wischmeier and Smith, 1978; Renard et al., 1997; Foster, 2004). However, the most effective use of these models outside of the United States, where it was developed, requires that regional values for each factor be developed based on local data and conditions (Wischmeier, 1984). Computation of the R-factor involves the calculation and summation of rainfall erosivity for individual erosive storm events. An individual rainfall event was defined as a period of rainfall with at least six preceding and six succeeding non-precipitation hours. The erosivity for each individual event is the $\mathrm{EI}_{30}$, which is the product of a storm's kinetic energy $(\mathrm{E})$ and its maximum 30-min rainfall intensity $\left(\mathrm{I}_{30}\right)$ (Wischmeier and Smith, 1958). It reflects the combined driving processes of detachment and transport by raindrops and runoff at the hillslope scale (Wischmeier, 1976). The $\mathrm{EI}_{30}$ and R-factor equations developed by Wischmeier were based on more than 8000 plot years of measured soil erosion data in the eastern half of the United States (Wischmeier, 1959). Foster et al. (1982) evaluated 21 indices of rainfall-runoff erosivity factors for individual storms and found that these factors did not significantly improve soil loss prediction as compared 
with $\mathrm{EI}_{30}$.

The method for calculating $\mathrm{EI}_{30}$ requires hyetograph data for a storm, and the data series should have more than 20 years of record in order to include dry and wet climate periods (Wischmeier, 1976). Due to the limited availability of hyetograph data, statistical models have been developed that relate more commonly available data, such as daily (Richardson et al., 1983; Bullock et al., 1989; Yu and Rosewell, 1996a; Petkovsek and Mikos, 2004; Angulo-Martinez and Begueria, 2009), monthly (Renard and Freimund, 1994; Yu and Rosewell, 1996b; Ferro et al. 1999) and annual rainfall (Bonilla and Vidal, 2011; Lee and Heo, 2011), to erosivity calculated from hyetograph data. Three aspects of the R-factor are potentially useful for soil erosion estimations. One is the average annual rainfall erosivity for predicting average annual soil loss. The second is the seasonal distribution curve of rainfall erosivity, the most commonly used format being cumulative erosivity in 24 half-month intervals. This allows the model to reflect the interactions of the cropping system management and rainstorm distributions (Wischmeier and Smith, 1978). The third is event or daily rainfall erosivity, which is important in soil loss recurrence analysis and the non-point source pollution assessment (Knisel, 1980; Kinnell, 2000).

Models for calculating erosivity at all temporal scales using event or daily rainfall are attractive since they can satisfy the three usage requirements mentioned above. A power law function has been generally used for estimating erosion index $\mathrm{EI}_{30}$ from event or daily rainfall amounts (Ateshian, 1974; Richardson et al., 1983). In early studies, event rainfall amount was used (Ateshian, 1974; Lombardi, 1979; Cooley, 1980). However, more long term series of daily rainfall amounts are available compared to event rainfall amount records. Richardson et al. (1983) first presented a statistically-based power law function for estimating erosion index $\mathrm{EI}_{\mathbf{3 0}}$ from daily rainfall amounts, which was evaluated in the eastern and central United States and proved to be an operational tool for erosion assessment (Haith and Merrill, 1987; Selker et al., 1990). In the development of the Richardson model, one event was assumed to occur within one day (Richardson et al., 1983). Elsenbeer et al. (1993) demonstrated the daily rainfall amount predicted the $\mathrm{R}$ factor as well as the event rainfall amount when the Richardson model was calibrated in the Amazon Basin. 
However, it is recognized that daily rainfall is not always synonymous with event rainfall. A daily rainfall amount may include only one event, multiple events, or only part of an event (Richardson et al., 1983). Bagarello and D'Asaro (1994) demonstrated that daily rainfall in many cases in the Mediterranean area cannot be assumed as representative of the individual event, and a rule for grouping daily rainfall amounts was developed and tested. Monthly summations of the $\mathrm{EI}_{30}$ index were used to develop the relationship (Yu and Rosewell, 1996a; Yu, 1998; Yu et al., 2001). When a storm spanned over midnight at the crossover between two months, the $\mathrm{EI}_{30}$ value for that storm was partitioned to individual months in proportion the amount of rainfall in that month. A relationship between the $\mathrm{EI}_{30}$ index for half month periods and the sum of estimated daily erosivity from daily rainfall amounts during the half month periods has been developed for China (Zhang et al., 2002). All of these models (Bagarello and D'Asaro, 1994; Yu and Rosewell, 1996a; Yu, 1998; Yu et al., 2001; Zhang et al., 2002; Zhu and Yu, 2015) were aimed at the average annual rainfall erosivity and its seasonal variations, while attention has not been paid to estimations of daily rainfall erosivity.

Daily erosivity has been defined in some work as the product of kinetic energy in a day and the maximum 30-min rainfall intensity during this day (Bullock et al., 1989; Capolongo et al., 2008) and R factor was the summation of all daily erosivity. No attempt was needed in these cases using the daily data to separate individual events, however, the $\mathrm{R}$ factor calculated in this way will be slightly different from the R values defined in the context of the USLE in Wischmeier and Smith (1958) because daily and event rainfall amounts are not synonymous (Bullock et al., 1989).

Based on simple power law form of the Richardson model, a sinusoidal or cosinusoidal function was subsequently introduced to describe the annual cycle of the coefficient of the power law function in order to represent seasonal differences in rainfall characteristics (Yu and Rosewell, 1996a; Yu, 1998; Yu et al., 2001; Capolongo et al., 2008; Zhu and Yu, 2015), which was considered to perform best among models included in a comparison study (Angulo-Martinez and Begueria, 2009). The China Meteorological Administration (CMA, 2003) requires that the maximum 60-min rainfall amount $\left(\mathrm{P}_{60 \mathrm{~min}}\right)_{\mathrm{d}}$ be compiled at government weather stations. We and others (Wang et al., 1995; Yin et al., 2007) hypothesize that the introduction of the index $\left(\mathrm{P}_{60 \mathrm{~min}}\right)_{\mathrm{d}}$ 
could improve the estimation of the $\mathrm{EI}_{30}$ index over the use of only daily data, since the $\left(\mathrm{P}_{60 \mathrm{~min}}\right)_{\mathrm{d}}$ reflects the shorter interval intensity compared to the daily rainfall amount.

Previous research has focused on estimating annual average and seasonal scales of rainfall erovisity from readily available daily rainfall. The overall objective of this study was to calibrate and validate three relationships for estimating daily scale of erosivity from daily rainfall. The first two used power functions of only daily rainfall totals for estimating erosivity. One was fitted with different coefficients in warm and cool seasons, and the second used a sinusoidal relationship in order to represent seasonal differences in storm characteristics. The third relationship utilized daily rainfall totals and the daily maximum 60-min rainfall amount to estimate daily rainfall erosivity. We also investigated the relationship between daily and event rainfall amounts and statistically evaluated and determined the best value for delineating the threshold between erosive and non-erosive daily rainfall amounts.

\section{Data and Methods}

\subsection{Database}

The eastern part of China is mainly influenced by the water erosion, compared to the western part, which is mainly influenced by the wind erosion and freeze-thaw erosion (Xin and Jiang, 1982). Sixteen weather stations with one-minute resolution rainfall data (Data M) distributed over the eastern water-erosion region of China were collected (Fig.1, Table 1). The periods of record for 14 of them were 1961 through 2000, and those for Wuzhai (53663) and Yangcheng (53975) in Shanxi province were 1971 through 2000. Data M were obtained using siphon, self-recording rain gauge observations (Wang et al., 2004). These were the data used exclusively in the analyses of erosivity.

Daily rainfall data (Data D) observed by simple rain gauges from these 16 stations were also collected to conduct quality control of Data M. Data M and Data D were compared day by day and those days with deviation more than $0.5 \mathrm{~mm}$ when the daily rainfall amount was less than 5 $\mathrm{mm}$ and more than $10 \%$ when the daily rainfall amount was greater than or equal to $5 \mathrm{~mm}$ were marked as questionable days and were not used in this analysis (after Wang et al., 2004). Data M 
in the earlier years of record tended to have more days with missing or suspicious observations.

Therefore, Data M and Data D were compared year by year to decide which years were "effective" years for using Data M. An effective year had relative deviation for yearly rainfall amount of no more than $15 \%$, when Data M was compared with Data D. The results showed that effective years were no less than 29 years for all stations, of which six stations had effective years no less than 38 years. Only the effective years were analyzed (Table 1). Note that though there were missing data in the information used, Data D was used only for quality control purposes and the data used in the analysis, Data $\mathrm{M}$, were internally consistent in that only the data from effective years were used in all comparisons reported. Thus relationships derived for daily erosivities are not biased by missing data.

For six stations in the northern part of China (including stations in Heilongjiang, Shanxi and Shaanxi provinces), only the period from May to September was used because in winter the siphon, self-recording rain gauges were not used in order to avoid freeze damage. Data for the whole year were used for the remaining ten stations located in the southern part of China. Ten stations including Nenjiang, Wuzhai, Suide, Yan'an, Chengdu, Suining, Neijiang, Fangxian, Kunming and Fuzhou, which are marked with dots in Fig. 1, were used as calibration stations to determine model parameters. The other six stations, including Tonghe, Yangcheng, Xichang, Huangshi, Tengchong and Changting, which are marked with triangles in Fig. 1, were used as validation stations to assess the models. Since the data for every station in each area have comparable record length and quality, one validation station was randomly selected for each area and the rest stations belonged to the calibration group.

To detect if there was any difference between stations for calibration and those for validation, a cross validation analysis was carried out as follows: (1) estimating parameter values from ten calibration stations (parameter set C) and from six validation stations (parameter set V); (2) using parameter set $\mathrm{C}$ to estimate $\mathrm{R}$ factor for six validation stations and parameter set $\mathrm{V}$ to estimate $\mathrm{R}$ factor for ten calibration stations; (3) the efficiency of the two parameter sets in estimating $\mathrm{R}$ factor was compared.

\subsection{Daily $R$ determination using 1-min rainfall data}



duration of rainfall with the dry periods less than "minimum dry-period duration" (MDPD, Bonta, 2004). If the dry period in a duration equals or is greater than MDPD, the duration was separated into two events. The MDPD is 6 hours in this study (Wischemier and Smith, 1978). An erosive rainfall event was initially defined as one with rainfall amount $\geqslant 12 \mathrm{~mm}$, following Xie et al. (2002). The dividing point of datelines for meteorological stations in China is 20:00 Beijing Time (BJT). The daily rainfall summarizes the 24-hour rainfall amount occurring from 20:00 BJT of the previous day until 20:00 BJT of the current day. There are four possibilities for the occurrence of an erosive event relative to the daily time period. Type I is a day where only one erosive event occurs, and that event begins and finishes in the same day, in which case

$$
\mathrm{R}_{\text {day }}=\mathrm{EI}_{30}
$$

where $\mathrm{R}_{\text {day }}$ is rainfall erosivity for the day. The second category (Type II) occurs when more than one rainfall event occur in one day, and all the events are fully within that day, in which case:

$$
\mathrm{R}_{\text {day }}=\sum_{\mathrm{i}=1}^{\mathrm{n}} \mathrm{E}_{\mathrm{i}} \cdot\left(\mathrm{I}_{30}\right)_{\mathrm{i}}
$$

where $\mathrm{n}$ is the number of rainfall events in the day, $\mathrm{E}_{\mathrm{i}}$ and $\left(\mathrm{I}_{30}\right)_{\mathrm{i}}$ are the total rainfall energy and the maximum 30-min intensity, respectively, for the $i^{\text {th }}$ event. The third category (Type III) is when only a part of a rainfall event occurs in one day. Then

$$
\mathrm{R}_{\text {day }}=\mathrm{E}_{\text {day_d }} \cdot \mathrm{I}_{30}
$$

where $E_{\text {day_d }}$ is the rainfall energy generated by the part of rainfall that occurred in the $d^{\text {th }}$ day and $\mathrm{I}_{30}$ is the maximum 30-min intensity for the entire event. For example, consider an event that extends into three different sequential days $\left(d_{1}, d_{2}\right.$ and $\left.d_{3}\right)$. In that case $E_{\text {day_1 }_{1}}$ represents the rainfall energy generated by the rainfall that occurred in the first day, $d_{1}$, and $E_{d a y \_2}$ represents the rainfall energy for the second day, $d_{2}$, etc. Note that $I_{30}$ is the same value for all three days. All the other situations were integrated into the category of Type IV. These were when: (1) one day includes at least one complete event plus part of another event; (2) one day includes one part of an event and 
one part of another event; and (3) one day includes no less than one event, a part of an event also occurring in the previous day and a part of an event that extends into the next day. Daily erosivity for Type IV category can be calculated by combining equations (2) and (3).

Erosivities for bi-monthly, monthly, yearly and multi-year time periods, t, were calculated as the summation of the daily erosivity values:

$$
R_{t}=\sum \mathrm{R}_{\text {day }}
$$

Rainfall storm energies were calculated using the equation recommend by Foster (2004) for RUSLE2:

$$
\begin{gathered}
E=\sum_{r=1}^{n}\left(e_{r} \cdot P_{r}\right) \\
e_{r}=0.29\left[1-0.72 \exp \left(-0.082 i_{r}\right)\right]
\end{gathered}
$$

where $\mathrm{E}$ is the individual storm energy $\left(\mathrm{MJ} \mathrm{ha}^{-1}\right), \mathrm{e}_{\mathrm{r}}$ is the unit rainfall kinetic energy for the $\mathrm{r}^{\text {th }}$ minute $\left(\mathrm{MJ} \mathrm{ha}^{-1} \mathrm{~mm}^{-1}\right), \mathrm{P}_{\mathrm{r}}$ is the minute rainfall amount $(\mathrm{mm})$, and $\mathrm{i}_{\mathrm{r}}$ is the rainfall intensity for the $\mathrm{r}^{\text {th }}$ minute.

\subsection{The delineation of erosive daily rainfall}

An erosive event that occurs across the dividing point of daily rainfall (such as 20:00 BJT for meteorological stations in China) may be divided into two (or more) daily rainfall amounts, and it is quite possible the erosive event threshold $(12 \mathrm{~mm})$ is not exceeded for one or more of these days. Research has shown that convective precipitation usually originates in the afternoon in warm, tropical, continental climates because of the local surface heating maxima (Yin et al., 2009). For example, the highest probability of hourly rainfall is at approximately 16:00 BJT for most inland areas of China (Yin et al., 2009). An event that originates at 16:00 BJT and lasts for more than four hours results in the event rainfall amount being separated into two consecutive days when the daily rainfall is calculated. If an erosive event is divided into two or more days, there is a probability that both parts of the storm will not be selected as erosive because one or both of the daily rainfall amounts will be lower than the erosivity threshold of $12 \mathrm{~mm}$. Therefore, the 
statistically best-fit threshold of erosive daily rainfall could be expected to be less than the $12 \mathrm{~mm}$ that defines the erosive event rainfall.

To compensate for this, we evaluated the threshold for the daily (as opposed to event) erosive rainfall by optimizing daily totals of erosivity to event totals of erosivity. This was done by decreasing the daily threshold value in increments of $0.1 \mathrm{~mm}$ from $12 \mathrm{~mm}$, until the mean relative deviation (MRD) of erosivity for the 16 stations reached a minimum as follows:

$$
\begin{gathered}
R_{\text {annual_evert }}(s)=\frac{1}{Y} \sum_{y=1}^{Y} \sum_{m=1}^{M}\left(E I_{30}\right)_{\text {event_m }} \\
R_{\text {annual_day }}(s)=\frac{1}{Y} \sum_{y=1}^{Y} \sum_{k=1}^{K}\left(E I_{30}\right)_{\text {day_k }} \\
R D(s)=\frac{R_{\text {annual_day }}(s)-R_{\text {annual_evart }}(s)}{R_{\text {annual_event }}(s)} \\
M R D=\frac{1}{S} \sum_{s=1}^{S} R D(s
\end{gathered}
$$

where $R_{\text {annual_event }}(s)$ is the average annual rainfall erosivity based on equations (5)-(7) using erosive events from the one-minute rainfall data for the $\mathrm{s}^{\text {th }}$ station $\left(\mathrm{MJ} \mathrm{mm} \mathrm{ha}^{-1} \mathrm{~h}^{-1} \mathrm{y}^{-1}\right) \cdot \mathrm{R}_{\text {annual_day }}(\mathrm{s})$ is the average annual erosivity based on equations (1)-(3) and Eq. (8) based on the one-minute rainfall data for the same station $\left(\mathrm{MJ} \mathrm{mm} \mathrm{ha} \mathrm{h}^{-1} \mathrm{~h}^{-1} \mathrm{y}^{-1}\right)$. M represents the total number of erosive events for the $\mathrm{y}^{\text {th }}$ year, and $\mathrm{K}$ stands for the total number of erosive days for the same year. $\mathrm{Y}$ is the total number of years of the data series for the $s^{\text {th }}$ station. $\mathrm{RD}(\mathrm{s})$ is the relative difference between $\mathrm{R}_{\text {annual_day }}(\mathrm{s})$ and $\mathrm{R}_{\text {annual_event }}(\mathrm{s})$ for the $\mathrm{s}^{\text {th }}$ station $(\%)$. $\mathrm{S}$ stands for the number of the stations. MRD is the mean RD for all 16 stations (\%).

\subsection{The development of daily rainfall erosivity models}

Three different models were assessed, which were a power law function with different coefficient values in cold and warm seasons (termed as Model I, equation 11), a power law function with sinusoidal relationship reflecting seasonal variations of coefficient (termed as Model II, equation 12), and a linear function relating daily rainfall erosivity with the product of daily rainfall amount and daily maximum 60-min rainfall amount (termed as Model III, equation 13). Model I: It is based on the power law equation originally proposed by Richardson et al. (1983): 


$$
\mathrm{R}_{\text {day }}=\alpha \mathrm{P}_{\mathrm{d}}^{\beta}
$$

where $\mathrm{P}_{\mathrm{d}}(\mathrm{mm})$ is the daily rainfall depth, calculated from one-minute resolution data (Data M); $\alpha$ and $\beta$ were empirically calculated for each month at every station minimizing the sum of square errors. Months with daily erosive sample sizes less than 15 over the period of record were not included, thus for four northern calibration stations there were a total of 20 month/station combinations used. The periods were from April through October for Chengdu, Suining, Neijing and Fangxian, from April through November for Kunming, and for the whole year for Fuzhou. The total number of month/station combinations for six southern calibration stations were 48 . Monthly $\alpha$ and $\beta$ values from the ten stations were fitted into a power law relationship (Yu, 1998). Parameter $\beta$ was set to be the average value of the ten calibration stations, and the parameter $\alpha$ was calibrated separately one for the cool season (Oct.-Apr.) and another for the warm season (May-Sept.), respectively, following Richardson et al. (1983).

Model II: It is based on the power law equation with sinusoidal relationship reflecting seasonal variations of coefficient $\alpha$ originally proposed by Yu and Rosewell in 1996:

$$
\mathrm{R}_{\mathrm{day}}=\alpha_{1}[1+\eta \cos (2 \pi \mathrm{fj}-\omega)] \mathrm{P}_{\mathrm{d}}^{\beta_{1}}
$$
where $\mathrm{j}$ is the month from 1 to 12 , representing January to December; $f$ is $1 / 12 ; \omega$ is $7 \pi / 6$ (since the rainfall erosivity is highest in July for most stations in China). The procedure suggested by Yu et al. (2001) was used to obtain the parameter values $\alpha_{1}, \eta$ and $\beta_{1}$. The optimized parameters were obtained by seeking the minimum sum of square errors in terms of monthly measured and estimated erosivity values. However, for six of 16 stations optimum parameters were not obtainable. Therefore, Parameter $\beta_{1}$ was set to be the average value of the ten calibration stations, monthly $\alpha$ values were averaged month by month and a sinusoidal function was fit using least-squared regression to describe the seasonal variations of $\alpha$. Model III: A linear function relating daily rainfall erosivity with the product of daily rainfall amount and daily maximum 60-min rainfall amount.

$$
\mathrm{R}_{\text {day }}=\kappa \mathrm{P}_{\mathrm{d}}\left(\mathrm{P}_{60 \min }\right)_{\mathrm{d}}
$$

where $\left(\mathrm{P}_{60 \mathrm{~min}}\right)_{\mathrm{d}}(\mathrm{mm})$ is the maximum 60-min rainfall in one day, which was derived from 
one-minute resolution data; $\kappa$ is the parameter to be determined by minimizing the sum of squared differences between the estimates and the values calculated from the measured one-minute precipitation data. The 60 minute maximum rainfall term was of interest in particular because of its widespread availability in China. Linear regressions were used to relate $R_{\text {day }}$ to $\mathrm{P}_{d} \mathrm{P}(60 \mathrm{~min}){ }_{\mathrm{d}}$ for each of the 10 calibration stations. Statistical analyses showed that the regression intercepts were not significant different from zero at 95\% significant level (Snedecor and Cochran, 1989), thereby the regression lines were forced through the origin and equation (13) included only slope parameters. $\kappa$ in equation (13) was the averaged value of slope parameters for ten calibration stations.

\subsection{The assessment of the models}

In RUSLE (Renard et al., 1997), one year was divided into 24 half-month parts and the average half month erosivity index $R_{\text {ave_half }}$ was required to reflect the seasonal variation of the $R$ factor. The period from the first day through the $15^{\text {th }}$ day belonged to the first half of the month and the remaining days belonged to the second half of the month. Values of $R_{\text {day }}$ were then summed to calculate $R_{\text {ave_half, yearly erosivity index }} R_{\text {year }}$ and average annual erosivity index $\mathrm{R}_{\text {annual. }}$. After the three models were calibrated with one minute data from the 10 calibration stations, the performance of the relationship was assessed by computing the coefficient of determination $\left(\mathrm{r}^{2}\right)$, the symmetric mean absolute percentage error $\left(\mathrm{MAPE}_{\mathrm{sym}}\right)$ and Nash-Sutcliffe model efficiency coefficient (ME) using the validation data from the remaining six stations. $\mathrm{MAPE}_{\text {sym }}$ was calculated as follows (Armstrong, 1985):

$$
\operatorname{MAPE}_{\mathrm{sym}}=\frac{1}{\mathrm{~m}} \sum_{\mathrm{k}=1}^{\mathrm{m}}\left|\frac{\mathrm{R}_{\mathrm{sim}}(\mathrm{k})-\mathrm{R}_{\mathrm{obs}}(\mathrm{k})}{\left(\mathrm{R}_{\mathrm{sim}}(\mathrm{k})+\mathrm{R}_{\mathrm{obs}}(\mathrm{k})\right) / 2}\right|
$$

where $\mathrm{R}_{\mathrm{obs}}$ is the measured rainfall erosivity for one day or a period of time such as average half month, yearly and average annual based on one-minute resolution rainfall data. $\mathrm{R}_{\text {sim }}$ is the estimated value for the same day or the same period using equation 11 or equation 12 based on daily rainfall totals, or equation 13 based on daily rainfall totals and the maximum 60-min rainfall amount in one day. The $\mathrm{MAPE}_{\mathrm{sym}}$ reflects the deviation of the simulation from the observation. 


$$
M E=1-\frac{\sum_{k}^{m}\left[R_{\text {sim }}(k)-R_{o b s}(k)\right]^{2}}{\sum_{k}^{m}\left[R_{o b s}(k)-\overline{R_{o b s}}(k)\right]^{2}}
$$

The ME compares the simulated and measured values relative to the line of perfect fit (1:1 line of measured equaling predicted). It is a combined measure of linearity, bias, and relative differences between the measured and predicted values. The maximum possible value of ME is 1 , and higher the value the better the model fit. An efficiency of $M E<0$ indicates that the single value of the mean of the measured data is a better predictor of the data than the model. $\mathrm{MAPE}_{\mathrm{sym}}$ and ME were calculated station by station for six validation stations and their mean values for all stations were determined. $\mathrm{R}_{\mathrm{obs}}$ has only one value for each station for the annual average scale of $\mathrm{R}$ estimation, and hence ME was not reported for average annuals.

\section{Results}

\subsection{Data summary and the relationship between daily and event rainfall}

Average annual rainfall ranged from 353.8 to $1590.7 \mathrm{~mm}$, and average annual erosivity varied from 781.9 to $8258.5 \mathrm{MJ} \mathrm{mm} \mathrm{ha}{ }^{-1} \mathrm{~h}^{-1} \mathrm{y}^{-1}$ (Table 1). A total of 10,891 erosive events were used in the study. The ten calibration stations had 5,942 erosive events and the six validation stations had 4,949 erosive events.

Most of the days belonged to either Types I or III (Fig. 2). For the average of 16 stations, $43.2 \%$ of days belonged to Type III, followed by Type I (40.2\%), Type IV (12.2\%) and Type II (4.4\%). Stations in the southwestern part including Chengdu, Xichang, Suining, Neijiang, Tengchong and Kunming tended to have more Type I (49.9\%) than Type III (34.4\%), whereas those in the southeastern part including Fangxian, Huangshi, Fuzhou and Changting tended to have more Type III (57.3\%) than Type I (25.0\%) days.

\subsection{Determination of the erosive daily rainfall threshold}

When the erosive daily rainfall threshold was set to $12 \mathrm{~mm}$, average annual erosivity values were $1.1 \%-6.2 \%$ lower than measured $\mathrm{R}$ values defined in the context of the USLE (Table 2). When the erosive daily rainfall was set to be $9.7 \mathrm{~mm}$, for two stations there were no 
underestimations compared to the hyetograph data; six stations had slightly higher annual erosivity values with the average relative deviation of $1.1 \%$, whereas the remaining eight stations had slightly lower values, with the average relative deviation being $-0.9 \%$. The average relative deviation for all of 16 stations reached the minimum (-0.1\%), therefore, we used the erosive daily rainfall threshold of $9.7 \mathrm{~mm}$. When the daily erosive rainfall threshold was set to be $10 \mathrm{~mm}$, the average relative difference was $-0.5 \%$, which was a negligible difference. The threshold of $10 \mathrm{~mm}$ corresponds to the specifications for surface meteorological observation by China Meteorological Administration (CMA, 2003), where daily rainfall is classified into four levels. Daily rainfall amounts of less than $10 \mathrm{~mm}$ belong to the light rain, those of $10-25 \mathrm{~mm}$ belong to the moderate rain, and those of 25-50 $\mathrm{mm}$ are considered heavy rain. Daily rainfall amounts greater than $50 \mathrm{~mm}$ are classified as "rainstorms". For ease of use, taking $10 \mathrm{~mm}$ as the erosive rainfall threshold will not bring about significant deviation from our results.

\subsection{Model calibration}

The monthly $\alpha$ and $\beta$ values for the power law function, Model I (eq. 11), were highly correlated (Fig. 3). The relationship between $\alpha$ and $\beta$ based on 68 months of data was:

$$
\log (\alpha)=2.19-(1.58 * \beta) \quad r^{2}=0.95
$$

It can be concluded that the coefficient $\alpha$ seems to have a sinusoidal pattern similar with the rainfall for the four northern stations (Fig. 4 (a) and (b)). Except Yan'an, the other three stations have maximum monthly rainfall in July. For Yan'an station, rainfall in August is slightly more than that in July. Parameters of $\alpha$ in Neijiang and Yan'an had a maximum value in July, whereas in Wuzhai the maximum value of $\alpha$ appeared in August and in Suide it was in June and August rather than in July. For six stations in the southern part, the sinusoidal pattern of rainfall was significant whereas that of coefficient $\alpha$ was not so obvious (Fig. 4 (c) and (d)). For Fuzhou station, the largest monthly rainfall appeared in June, and the second largest was in August, which was not similar with the other five stations, with the maximum monthly rainfall occurring in July. For Fuzhou station, the largest $\alpha$ was located in July and the second largest is in October. 
season for ten stations was 0.3937 with a standard deviation of 0.0612 , and for the cool season it was 0.3101 with a standard deviation of 0.0787 . It was clear that the geographic differences in $\alpha$ were smaller than those between warm and cool seasons. The two sample t-test showed that the differences in $\alpha$ in warm and cool seasons were significant at a 95\% level (Snedecor and Cochran, 1989). Therefore, Model I was found to be:

$$
\mathrm{R}_{\text {day }}=\alpha \mathrm{P}_{\mathrm{d}}^{1.7265}
$$

where parameter $\alpha$ equals 0.3937 in the warm season and 0.3101 in the cool season. Model II was:

$$
R_{\text {day }}=0.2686\left[1+0.5412 \cos \left(\frac{\pi}{6} j-\frac{7 \pi}{6}\right)\right] P_{d}^{1.7265}
$$

Model III, using the combination of daily rainfall amount $\mathrm{P}_{\mathrm{d}}$ and the maximum 60-min rainfall in one day $\left(\mathrm{P}_{60 \mathrm{~min}}\right)_{\mathrm{d}}$, was:

$$
\mathrm{R}_{\text {day }}=0.3522 \mathrm{P}_{\mathrm{d}}\left(\mathrm{P}_{60 \text { min }}\right)_{\mathrm{d}}
$$

For most cases in China (not including the data used in this study), the maximum hourly rainfall $\left(\mathrm{P}_{1 \mathrm{~h}}\right)_{\mathrm{d}}$ is available only for clock hours (e.g., 10:00 -11:00) rather than any 60-min period with the maximum amount of precipitation. $\left(\mathrm{P}_{1 \mathrm{~h}}\right)_{\mathrm{d}}$ can never be greater than $\left(\mathrm{P}_{60 \mathrm{~min}}\right)_{\mathrm{d}}$ because the latter is not restricted by the clock hour. When $\left(\mathrm{P}_{1 \mathrm{~h}}\right)_{\mathrm{d}}$ index was used instead of $\left(\mathrm{P}_{60 \mathrm{~min}}\right)_{\mathrm{d}}$ in equation $19, \kappa$ was found to be 0.3998 instead of 0.3522 .

Cross-validation results showed that the three models derived by calibrating the six stations in the validation group were as follows:

$$
\mathrm{R}_{\text {day }}=\alpha \mathrm{P}_{\mathrm{d}}{ }^{1.7394}
$$

$$
R_{\text {day }}=0.2377\left[1+0.8289 \cos \left(\frac{\pi}{6} \mathrm{j}-\frac{7 \pi}{6}\right)\right] \mathrm{P}^{1.7394}
$$

$$
\mathrm{R}_{\text {day }}=0.3488 \mathrm{P}_{\mathrm{d}}\left(\mathrm{P}_{60 \mathrm{~min}}\right)_{\mathrm{d}}
$$


values for stations in the validation group (Equations 20-22) were similar to those from the calibration group (Equations 17-19) and the difference in model efficiency in predicting the $\mathrm{R}$ factor between parameter values for the two groups were small (Fig. 5), which suggested the choice of calibration and validation stations was not sensitive.

\subsection{Model validation}

Model I and Model II require erosive daily rainfall data. Both models generated reasonable approximations of the average annual R-factor (Table 3). For Model I, the MAPE $\mathrm{sym}_{\text {ranged from }}$ $3.8 \%$ for Huangshi station to $16.6 \%$ for Tengchong station, with the mean of six stations being $11.0 \%$ (Table 3 ). For the best case at the Huangshi station, one-minute resolution rainfall data of 32 effective years showed that the R-factor was 6049.4 MJ mm ha ${ }^{-1} \mathrm{~h}^{-1} \mathrm{y}^{-1}$ (Table 1), which was similar to the estimated value of $6283.7 \mathrm{MJ} \mathrm{mm} \mathrm{ha}^{-1} \mathrm{~h}^{-1} \mathrm{y}^{-1}$. For the worst case at the Tengchong station, the R-factor value based on 36 years of one-minute resolution data was $3648.9 \mathrm{MJ} \mathrm{mm}$ $\mathrm{ha}^{-1} \mathrm{~h}^{-1} \mathrm{y}^{-1}$, and the estimation from daily rainfall data was $4309.4 \mathrm{MJ} \mathrm{mm} \mathrm{ha}^{-1} \mathrm{~h}^{-1} \mathrm{y}^{-1}$.

Model II performed better than Model I at all of the temporal scales, particularly for seasonal variations (Table 3), for which the average $\mathrm{MAPE}_{\mathrm{sym}}$ of $\mathrm{R}_{\text {ave_half }}$ for Model I was $32.1 \%$ and that for Model II was 25.5\%. Fig. 6 (a) and (c) illustrate the seasonal variations of R for the Tonghe station in Heilongjiang province and Tengchong station in Yunnan province. The general pattern within the year was described well by the Model II.

When the $\mathrm{R}$ values generated by Model II were compared year by year with the observations, the MAPE $\mathrm{sym}_{\mathrm{s}}$ varied from $15.4 \%$ to $29.0 \%$, with an average of $21.8 \%$ (Table 3 ). The Nash-Sutcliffe model efficiency coefficient, ME, varied from 0.16 for Yangcheng station to 0.77 for Xichang station, with an average of 0.56 (Table 4). It can be seen that the general inter-annual variabilities and long term trends are reflected by the simulations (Fig. 6 (b) and (d)). In Yangcheng station, there was an extreme storm starting on the $30^{\text {th }}$ of July, 1982, with a rainfall amount of $339.2 \mathrm{~mm}$ and duration of 106 hours, which was partly responsible for the lower ME for this station. When the $\mathrm{EI}_{30}$ index for 1982 was excluded, the $\mathrm{ME}$ for the remaining 29 years increased to 0.38 for Model I and 0.41 for Model II. 
When the daily $\mathrm{R}$ values estimated using daily rainfall amount based on equation 18 (Model

II) were compared with those using one-minute resolution rainfall data, the $\mathrm{MAPE}_{\mathrm{sym}}$ varied from $57.2 \%$ to $78.9 \%$ with a mean of $65.7 \%$ among six data sets (Table 3, Fig. 7 (a) and (b)). Average Nash-Sutcliffe model efficiency was 0.57 (Table 4). These results suggested that the prediction efficiency is limited for estimating daily erosivity using only a daily rainfall amount index.

Model III using the combination of daily rainfall amount $\mathrm{P}_{\mathrm{d}}$ and daily maximum 60-min rainfall $\left(\mathrm{P}_{60 \mathrm{~min}}\right)_{\mathrm{d}}$, performed better than either Model I or II. Efficiency for the daily erosivity predictions was improved, with the average $\mathrm{MAPE}_{\mathrm{sym}}$ being 39.0\% and ME being 0.93, when a daily maximum hourly rainfall index was added (Table 3 and Table 4, Fig. 7 (c) and (d)).

\section{Discussion}

The relationship of exponent $\beta$ and coefficient $\alpha$ (equation 16) was very similar with that of Yu (1998), which was derived based on the data from the tropics, New South Wales, and South Australia (Fig. 3):

$$
\log (\alpha)=2.32-(1.64 \times \beta) \quad r^{2}=0.90
$$

Zhang et al. (2002) also reported strong correlation between the parameters $\alpha$ and $\beta$, who derived a power law relationship of:

$$
\alpha=21.586 \times \beta^{-7.1891} \quad \mathrm{r}^{2}=0.95
$$

For the convenience of comparison, the logarithmic relationship was derived using the parameters $\alpha$ and $\beta$ reported in Zhang et al. (2002) and was plotted in Fig. 3.

$$
\log (\alpha)=2.32-(1.52 \times \beta) \mathrm{r}^{2}=0.95
$$

The parameters $\alpha$ and $\beta$ for Zhang et al. (2002) were from 71 stations in China. All months for each station were combined to obtain the parameters $\alpha$ and $\beta$. Though the relationship was weak, they also found that $\beta$ was related with average daily erosive rainfall $\mathrm{P}_{\mathrm{d} 12}$ and average annual erosive rainfall $\mathrm{P}_{\mathrm{y} 12}$ : 


$$
\beta=0.8363+\frac{18.177}{\mathrm{P}_{\mathrm{d} 12}}+\frac{24.455}{\mathrm{P}_{\mathrm{y} 12}} \quad \mathrm{r}^{2}=0.44
$$

Bullock et al. (1990) reported the parameters $\alpha$ and $\beta$ from the stations in Saskatchewan province were significantly linearly related with mean annual rainfall, however, the relationship was not significant for the stations in Alberta and Manitoba provinces in Canada. Two linear relationships with mean annual rainfall as the independent variable were used to estimate $\alpha$ and $\beta$ where there is no hyetograph data available. Neither the relationship between monthly $\beta$ and $\mathrm{P}_{\mathrm{d} 12}$ or between monthly $\beta$ and $\mathrm{P}_{\mathrm{y} 12}$ for the ten calibration stations in this study were significant. Yu (1998) also concluded that the dependence of parameter $\beta$ on mean annual rainfall or seasonal rainfall was weak for Australia. The reason for this may be attributed to the parameters which were derived month by month for both Yu (1998) and this study and by all months for Zhang et al. (2002).

When we obtained ten pairs of $\alpha$ and $\beta$ by pooling all erosivity events for each station together and plotting a scatter diagram of the exponent $\beta$ and $\mathrm{P}_{\mathrm{d} 12}$, a weak linear trend existed with the determination coefficient being 0.41 , and a p-value of the F statistic being 0.0456 , which means the relationship is significant at a 95\% level of confidence. The relationship between $\beta$ and $\mathrm{Py}_{12}$ was not significant at a 95\% level, with a p-value of 0.0808 (Snedecor and Cochran, 1989). Although the relationship between the exponent $\beta$ and $\mathrm{P}_{\mathrm{d} 12}$ was statistically significant, a $\mathrm{p}$-value of 0.0456 suggested the correlation was not strong. The deviation of model output from measured values may be large if the parameter $\beta$ was not properly estimated, since it was an exponent in the power law model.

Richardson et al. (1983) concluded that there were no discernable spatial (between stations) patterns in the variation of $\beta$, and hence an average value of 1.81 was suggested. For 11 stations used by Richardson et al. (1983), the average of $\alpha$ for the warm season was 0.41 with a standard deviation of 0.24 , and for the cool season it was 0.18 with a standard deviation of 0.11 . The differences between the warm season and cool season were clear, which indicated that the same amount of rainfall in the warm season can generate $127.8 \%$ higher erosivity than that in the cool season, because the summer rains tended to be more intense than winter rains (Richardson et al., 1983). Average $\beta$ was 1.7265 in this study, which was only slightly lower than that (1.81) from Richardson et al. (1983). If coefficient $\alpha$ is held constant, the $\beta$ value of 1.7265 generates $17 \%$ 
lower rainfall erosivity for the daily rainfall of $10 \mathrm{~mm}$ and $32 \%$ lower for the daily rainfall of 100 mm compared with using the value of 1.81 . Coefficient $\alpha$ of 0.3937 for the warm season was similar with that (0.41) from Richardson et al. (1983), whereas that for the cool season was $72 \%$ higher than that from Richardson et al. (1983). The t-test showed that $\alpha$ for the warm season in this study was not significant different from that in Richardson et al. (1983), whereas $\alpha$ for the cool season was significantly different at a 95\% level (Snedecor and Cochran, 1989). Taking both $\alpha$ and $\beta$ into consideration, one would expect a lower rainfall erosivity for the warm season and a higher rainfall erosivity for the cool season for the same amount of rain in this study as compared to Richardson et al. (1983). Stations in the southern parts of China are affected by the monsoon system during the months of October through April, which may be the reason for the higher rainfall erosivity for the same amount of rain in the cool season for China than that for the U.S.A. data that were used in the previous study.

To assess if parameters developed in other parts of the world may be adopted in China and parameters developed for China in previous research are effective, parameters from Richardson (1983), Yu (1998), Yu et al. (2001), Zhang et al. (2002), Zhu and Yu (2015) were used to estimate R for six validation stations (Fig. 8). Except for the values given by $\mathrm{Yu}$ (1998) and Zhu and Yu (2015), parameters from the other three studies overestimated R. Parameters from Yu (1998) produced a reasonable result, with the average $\mathrm{MAPE}_{\text {sym }}$ of R being 14.3\%. Parameters from Zhu and $\mathrm{Yu}(2015)$ generated the average $\mathrm{MAPE}_{\mathrm{sym}}$ of $7.4 \%$, which performed as well as models in this study. Measured R factor in Fuzhou station is $5871.1 \mathrm{MJ} \mathrm{mm} \mathrm{ha}^{-1} \mathrm{~h}^{-1} \mathrm{y}^{-1}$ and parameters from Zhu and $\mathrm{Yu}$ (2015) overestimated erosivity, with the $\mathrm{MAPE}_{\text {sym }}$ being 18.2\% (Fig. 8). This may have been due to the use of two different sets of parameters, depending on whether $\mathrm{R}$ was greater than or lower than $6000 \mathrm{MJ} \mathrm{mm} \mathrm{ha}{ }^{-1} \mathrm{~h}^{-1} \mathrm{y}^{-1}$. The reason for the overestimation by Zhang et al. (2002) may be due to their use of a surrogate for the measured value of $\mathrm{EI}_{30}$. The surrogate used was $0.184 \mathrm{P}_{\mathrm{d}} \mathrm{I}_{10 \mathrm{~d}}$, which is the product of daily rainfall $\mathrm{P}_{\mathrm{d}}$ and the maximum 10-min intensity in a day $\mathrm{I}_{10 \mathrm{~d}}$, multiplied by a conversion factor of 0.184 . Although it was shown that the $\mathrm{P}_{\mathrm{d}} \mathrm{I}_{10 \mathrm{~d}}$ and $\mathrm{EI}_{30}$ were highly correlated (Xie et al., 2001), the use of $\mathrm{P}_{\mathrm{d}} \mathrm{I}_{10 \mathrm{~d}}$ instead of $\mathrm{EI}_{30}$ contributes to the uncertainty in the relationship. Results here suggested models developed in this study may need to be calibrated carefully before they are implemented in the other places. 
Selker et al. (1990) pointed out that there were inherent limitations in the prediction of extreme daily $\mathrm{EI}_{30}$ index by daily rainfall amount for erosivity, including factors associated with differences in kinetic energy and intensity which may be poorly represented by daily rainfall values. It is better to obtain higher temporal resolution rainfall data to reflect the short-time intensity information. Model III introduces a daily maximum hourly rainfall index that significantly improved the estimation of rainfall erosivity at different temporal scales because the peak 1-hr rainfall intensity is correlated with the peak 30-min rainfall intensity on a daily basis. However, it should be noted although Model III was shown to improve the estimation of rainfall erosivity, especially for daily $\mathrm{EI}_{30}$ values, Model I and II are still valuable because they have fewer and more easily satisfied data requirements.

Daily erosivity was assumed to be computed by using the rainfall energy generated by the part of rainfall that occurred in the day and the maximum 30-min intensity for the entire event for Type III storm (Equation 3). Consider a storm that spanned two days with the maximum 30-min intensity occurring in the second day. If total rainfall amount for the first day is greater than 9.7 $\mathrm{mm}$, the estimation of daily erosivity for the first day will be related to the daily rainfall amount and maximum 60-min intensity in the first day. However, the actual daily erosivity according to the assumption in this study was related to the daily rainfall energy in the first day and maximum 30-min intensity in the second day. Since the daily rainfall amount was highly correlated with the daily rainfall energy, the quality of the estimation depended mainly on the relationship between the maximum 60-min intensity in the first day and the maximum 30-min intensity in the second day. If it was a convective storm with relatively greater maximum peak intensity, the bias may be considerable. However, the convective storms usually originate in the afternoon and early evening due to diurnal variation of solar heating on the ground, and last for a relative short period. The probability for convective storms spanning across multiple days, with all these days having erosive daily rainfall, was low. The East-Asian monsoon system dominates most parts of eastern China and usually causes frontal storms (Ding, 2004). Often a great amount of water is carried by the warm front, causing the storm to last for several days with a large total rainfall amount. However, the intra-storm variability in intensity for frontal storms is relatively small, which results in the fact that the assumption of daily erosivity being estimated by the product of the rainfall 
energy generated by the part of rainfall that occurred in the day and the maximum 30-min intensity for the entire event for Type III storm probably does not create a large bias. The ME of $\mathrm{R}_{\text {day }}$ estimations by Model III was greater than 0.88 for six validation stations (Table 4 ), which suggests that it was an effective model in daily erosivity estimation in China.

\section{Conclusions}

A total of 10,891 erosive events from one-minute resolution rainfall data from 16 weather stations located over the eastern water-erosion-prone region of China were used to analyze empirical relationships between rainfall erosivity and a) daily rainfall amounts and b) daily rainfall amounts and maximum 60-min rainfall. The following conclusions can be drawn:

(1) For all days with erosive rainfall, $40.2 \%$ of days had one and only one event and $43.2 \%$ had only one erosive event, but that event occurred over more than one day. The remaining days with erosive rainfall experienced whole or parts of more than one erosive event.

(2) The best-fit threshold for dividing erosive and non-erosive daily rainfall was found to be 9.7 $\mathrm{mm}$, which is lower than the erosive event rainfall amount of $12 \mathrm{~mm}$.

(3) A power law relationship $R_{\text {day }}=\alpha \mathrm{P}_{d}{ }^{\beta}$ can be used to estimate rainfall erosivity by daily rainfall amount, $\mathrm{P}_{\mathrm{d}}$, when the hyetograph data is not available. We found no geographic pattern in the variation of $\beta$ for ten calibration stations, and an average value of 1.7265 is proposed. Model I, the simple power law relationship, had a best fit coefficient $\alpha$ of 0.3937 in the warm season and 0.3101 in the cool season. Coefficient $\alpha$ for Model II, which is the power law with seasonal variation, was fitted a sinusoidal curve representing temporal variation within the year.

(4) The average annual rainfall erosivity and its seasonal variations can be represented well by Model I and Model II. When average annual erosivity was compared with the observation, the symmetric mean absolute percentage error $\mathrm{MAPE}_{\mathrm{sym}}$ for Model I was $11.0 \%$ and that for Model II was $10.8 \%$. For average half-month erosivities, the $\mathrm{MAPE}_{\mathrm{sym}}$ were greater, at $32.1 \%$ for Model I and 25.5\% for Model II. 
(5) The efficiency of Model I and Model II for predicting daily EI index was limited. Model III used a combination of daily rainfall amount $\mathrm{P}_{\mathrm{d}}$ and the maximum 60-min rainfall $\left(\mathrm{P}_{60 \mathrm{~min}}\right)_{\mathrm{d}}$, resulting in the equation $\mathrm{R}_{\text {day }}=0.3522 \mathrm{P}_{\mathrm{d}}\left(\mathrm{P}_{60 \mathrm{~min}}\right)_{\mathrm{d}}$. Predictions using this equation were superior to the first two equations, particularly for the daily $\mathrm{EI}_{30}$ index, where the model efficiency increased to 0.93 from 0.55 and 0.57 for Models I and II.

(6) Finer, sub-daily temporal resolution of data, represented by the maximum 60 minute data, generated better results for daily rainfall erosivity values than did the use of only daily rainfall totals.

\section{Acknowledgements}

The authors would like to thank the Heilongjiang, Shanxi, Shaanxi, Sichuan, Hubei, Fujian, and Yunnan Meteorological Bureaus for supplying rainfall data. This work was supported by National Natural Science Foundation of China (No. 41301281), National Basic Research Program of China (973 Program) (No. 2007CB407203) and the China Scholarship Council. Thanks to Bofu Yu for his help in Model II calibration. Thanks to two reviewers for their valuable comments. The USDA is an equal opportunity employer.

\section{References}

[1] Armstrong, J.S., 1985. Long-range Forecasting: From Crystal Ball to Computer, 2nd. ed. Wiley: New York, USA.

[2] Angulo-Martinez M., Begueria S., 2009. Estimating rainfall erosivity from daily precipitation records: A comparison among methods using data from the Ebro Basin (NE Spain). J. Hydrol. $379,111-121$.

[3] Ateshian J.K.H., 1974. Estimation of rainfall erosion index. J. of the Irrig. And Drainage Div., Proc. of the ASCE 100(IR3), 293-307.

[4] Bagarello V., D'Asaro F., 1994. Estimating single storm erosion index. T. ASAE, 37(3), 785-791. 
[5] Bonta J.V., 2004. Development and utility of Huff curves for disaggregating precipitation amounts. Appl. Eng. Agric., 20(5), 641-653.

[6] Bonilla C.A., Vidal K.L., 2011. Rainfall erosivity in Central Chile. J. Hydrol. 410, 126-133.

[7] Bullock P.R., Dejong E., Kiss J.J., 1989. An assessment of rainfall erosion potential in southern Saskatchewan from daily rainfall records. Can. Agr. Eng. 32, 17-24.

[8] Capolongo D., Diodato N., Mannaerts C.M., Piccarreta M., 2008. Analyzing temporal changes in climate erosivity using a simplified rainfall erosivity model in Basilicata (southern Italy). J. Hydrol. 356, 119-130.

[9] China Meteorological Administration (CMA), 2003. Specifications for surface meteorological observation. Beijing: Meteorology Publishing House.

[10] Cooley K.R., 1980. Erosivity values for individual design storms. J. of the Irrig. and Drainage Div., Proc. of the ASCE 106(IR2), 135-144.

[11] Ding Y.H., 2004. Seasonal march of the East-Asian summer monsoon. In Chang C.P. (Eds.), East Asian Monsoon. World Scientific Series on Meteorology of East Asia (Vol. 2). World Scientific Publishing Co. Pte. Ltd.: Singapore.

[12] Elsenbeer H., Cassel D.K., Tinner W.A., 1993. Daily rainfall erosivity model for western Amazonia. J. Soil Water Conserv. 48(5), 439-444.

[13] Ferro V., Porto P., Yu B., 1999. A comparative study of rainfall erosivity estimation for southern Italy and southeastern Australia. Hydrolog. Sci. J. 44(1), 3-24.

[14] Foster G.R., 2004. User's reference guide: Revised Universal Soil Loss Equation (RUSLE2). U.S. Department of Agriculture, Agricultural Research Service, Washington, DC, USA.

[15] Foster G.R., Lombardi F., Moldenhauer W.C., 1982. Evaluation of rainfall-runoff erosivity factors for individual storms. T. ASAE 25(1), 124-129.

[16] Haith D.A., Merrill D. E., 1987. Evaluation of a daily erosivity model. T. ASAE 30(1), 90-93.

[17] Kinnell P.I.A., 2000. AGNPS-UM: Applying the USLE-M within the agricultural non-point 
583

584

[18] Knisel W.G., 1980. CREAMS: A Field-Scale Model for Chemicals, Runoff, and Erosion from Agricultural Management Systems. U.S. Department of Agriculture, Conservation Research Report No. 26.

[19] Lee J.H., Heo J.H., 2011. Evaluation of estimation methods for rainfall erosivity based on annual precipitation in Korea. J. Hydrol. 409, 30-48.

[20] Lombardi F., 1979. Universal Soil Loss Equation (USLE), runoff erosivity factor, slope length exponent, and slope steepness exponent for individual storms. $\mathrm{PhD}$ Thesis, Purdue University, W. Lafayette, Ind.

[21] Nash J.E., Sutcliffe J.V., 1970. River flow forecasting through conceptual models, Part 1 -a discussion of principles. J. Hydrol. 10(3), 282-290.

[22] Petkovsek G., Mikos M., 2004. Estimating the R factor from daily rainfall data in the sub-Mediterranean climate of southwest Slovenia. Hydrolog. Sci. J. 49(5), 869-877.

[23] Renard K.G., Foster G.R.,Weesies G.A., McCool D.K., Yoder D.C., 1997. Predicting soil erosion by water. U.S. Department of Agriculture, Agricultural Research Service, Agriculture Handbook 703.

[24] Renard K.G., Freimund J.R., 1994. Using Monthly Precipitation Data to Estimate the R-factor in the Revised USLE. J. Hydrol. 157, 287-306.

[25] Richardson C.W., Foster G.R., Wright D.A., 1983. Estimation of erosion index from daily rainfall amount. T. ASAE 26(1), 153-156.

[26] Selker J.S., Haith D.A., Reynolds J.E., 1990. Calibration and testing of a daily rainfall erosivity model. T. ASAE 33(5), 1612-1618.

[27] Snedecor G.W., Cochran W.G., 1989. Statistical Methods, eighth edition. The Iowa State University Press, Ames.

[28] Wang B.M., Lu Y.P., Zhang Q., 2004. The color scanning digitizing processing system of 
precipitation autographic record paper. J. Appl. Meteor. Sci. 15, 737-744 (in Chinese with English abstract).

[29] Wang W.Z., Jiao J.Y., Hao X. P., 1995. Distribution of rainfall erosivity R value in China. J. Soil Water Conserv., 9(4), 5-18(in Chinese with English abstract).

[30] Wischmeier, W.H., 1959. A rainfall erosion index for a universal soil loss equation. Soil Sci. Soc. Am. Proc. 23, 322-326.

[31] Wischmeier W.H., 1976. Use and issue of the universal soil loss equation. J. Soil Water Conserv. 31 (1), 5-9.

[32] Wischmeier W.H., 1984. The USLE: some reflections, W.H. Wischmeier talks about the USLE's development and use. J. Soil Water Conserv. 39(2), 105-107.

[33] Wischmeier W.H., Smith D.D., 1958. Rainfall energy and its relationship to soil loss. Tran. Am. Geophys. Union 39(2), 285-291.

[34] Wischmeier W.H., Smith D.D., 1965. Predicting rainfall-erosion losses from cropland east of the Rocky Mountains. U.S. Department of Agriculture, Agricultural Research Service, Agriculture Handbook 282.

[35] Wischmeier W.H., Smith D.D., 1978. Predicting Rainfall Erosion Losses: A Guide to Conservation Planning. U.S. Department of Agriculture, Agricultural Research Service, Agriculture Handbook 537.

[36] Xie Y., Liu B., Nearing M.A., 2002. Practical thresholds for separating erosive and non-erosive storms. T. ASAE 45(6), 1843-1847.

[37] Xie Y., Zhang W.B., Liu B.Y., 2001. Rainfall erosivity estimation using daily rainfall amount and intensity. B. Soil Water Conserv. 21(6), 53-56 (in Chinese with English abstract).

[38] Xin S.Z., Jiang D.Q., 1982. A synopsis on water and soil conservation in China. Beijing: Agriculture Press.

[39] Yin S.Q., Chen D., Xie Y., 2009. Diurnal variations of precipitation during the warm season over China. Int. J. Climatol., 29(8), 1154-1170.

[40] Yin S.Q., Xie Y., Nearing M.A., Wang C.G., 2007. Estimation of rainfall erosivity using 5to 60-minute fixed-interval rainfall data from China. Catena, 70(3), 306-312. 
635 [41] Yu B., 1998. Rainfall erosivity and its estimation for Australia's tropics. Aust. J. Soil Res. 36, $636 \quad 143-165$.

637 [42] Yu B., Rosewell C.J., 1996a. Rainfall erosivity estimation using daily rainfall amounts for 638 South Australia. Aust. J. Soil Res. 34, 721-733.

639 [43] Yu B., Rosewell C.J., 1996b. A robust estimatior of the R-factor for the universal soil loss equation. T. ASAE 39(2), 559-561.

641 [44] Yu B., Hashim G.M., Eusof Z., 2001. Estimating the R-factor with limited rainfall data: A case study from Peninsular Malaysia. J. Soil Water Conserv. 56(2), 101-105.

[45] Zhang W.B, Xie Y., Liu B.Y., 2002. Rainfall erosivity estimation using daily rainfall amounts. Sci. Geogr. Sin. 22(6), 705-711 (in Chinese with English abstract).

[46] Zhu Z.L, Yu B., 2015. Validation of rainfall erosivity estimators for mainland China. T. ASABE 58(1), 61-71.

647 


\section{Tables}

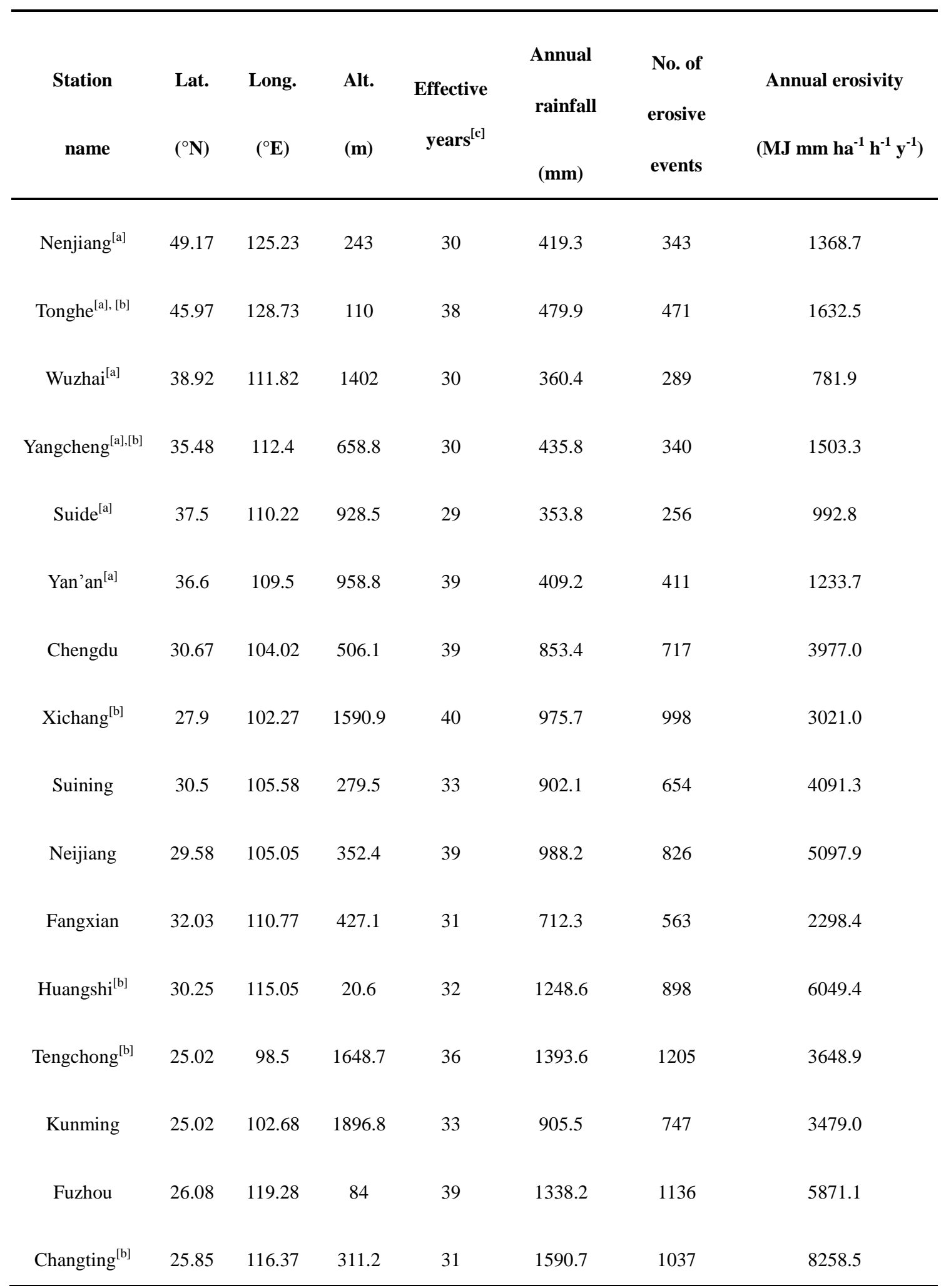

${ }^{[a]}$ For stations in the northern part of China, statistics of average annual rainfall, erosive events and average annual 
651 erosivity were based on data collected during May through September, whereas those for the remaining ten stations

652 were based on data collected during the whole year.

653

${ }^{[b]}$ Stations used for validation. The other ten stations were used for model parameter development.

$654{ }^{\left[{ }^{[c]}\right.}$ Effective years were those that were used in the study, with relative deviation for yearly rainfall amount no more

655 than $15 \%$ when one-minute resolution rainfall data were compared with daily resolution data.

656

657 

and $9.7 \mathrm{~mm}$, respectively.

\begin{tabular}{|c|c|c|c|c|c|c|c|c|c|}
\hline \multirow{2}{*}{$\begin{array}{c}\text { Station } \\
\text { name }\end{array}$} & \multirow{2}{*}{$\begin{array}{l}R_{\text {event }}^{[a]} \\
12 \mathrm{~mm}\end{array}$} & \multicolumn{4}{|c|}{$\mathbf{R}_{\text {daily }}{ }^{[\mathbf{b}]}$} & \multicolumn{4}{|c|}{$\mathbf{R} \mathbf{D}^{[\mathrm{c}]}$} \\
\hline & & $12 \mathrm{~mm}$ & $11 \mathrm{~mm}$ & $10 \mathrm{~mm}$ & $9.7 \mathrm{~mm}$ & $12 \mathrm{~mm}$ & $11 \mathrm{~mm}$ & $10 \mathrm{~mm}$ & $9.7 \mathrm{~mm}$ \\
\hline Nenjiang & 1368.7 & 1284.3 & 1332.1 & 1356.6 & 1362.3 & -6.2 & -2.7 & -0.9 & -0.5 \\
\hline Tonghe & 1632.5 & 1559.2 & 1594.0 & 1628.5 & 1640.5 & -4.5 & -2.4 & -0.2 & 0.5 \\
\hline Wuzhai & 781.9 & 739.8 & 757.5 & 786.6 & 791.1 & -5.4 & -3.1 & 0.6 & 1.2 \\
\hline Suide & 992.8 & 953.3 & 986.7 & 1010.5 & 1013.6 & -4.0 & -0.6 & 1.8 & 2.1 \\
\hline Yan'an & 1233.7 & 1184.1 & 1208.6 & 1226.7 & 1234.2 & -4.0 & -2.0 & -0.6 & 0.0 \\
\hline Yangcheng & 1503.3 & 1451.0 & 1469.3 & 1490.9 & 1500.5 & -3.5 & -2.3 & -0.8 & -0.2 \\
\hline Chengdu & 3977.0 & 3896.9 & 3924.0 & 3952.3 & 3960.1 & -2.0 & -1.3 & -0.6 & -0.4 \\
\hline Xichang & 3021.0 & 2936.5 & 2972.2 & 3010.3 & 3021.8 & -2.8 & -1.6 & -0.4 & 0.0 \\
\hline Tengchong & 3648.9 & 3569.8 & 3632.5 & 3703.9 & 3728.7 & -2.2 & -0.4 & 1.5 & 2.2 \\
\hline Kunming & 3479.0 & 3311.3 & 3365.6 & 3403.1 & 3429.1 & -4.8 & -3.3 & -2.2 & -1.4 \\
\hline Fangxian & 2298.4 & 2211.1 & 2242.2 & 2268.4 & 2272.2 & -3.8 & -2.4 & -1.3 & -1.1 \\
\hline Suining & 4091.3 & 4046.1 & 4071.6 & 4101.0 & 4105.0 & -1.1 & -0.5 & 0.2 & 0.3 \\
\hline Neijiang & 5097.9 & 5009.3 & 5047.3 & 5096.1 & 5107.0 & -1.7 & -1.0 & 0.0 & 0.2 \\
\hline Huangshi & 6049.4 & 5907.2 & 5951.3 & 5990.2 & 6004.5 & -2.4 & -1.6 & -1.0 & -0.7 \\
\hline Fuzhou & 5871.1 & 5617.0 & 5668.8 & 5735.7 & 5756.4 & -4.3 & -3.4 & -2.3 & -2.0 \\
\hline Changting & 8258.5 & 7944.0 & 8034.5 & 8117.9 & 8141.7 & -3.8 & -2.7 & -1.7 & -1.4 \\
\hline $\mathrm{MRD}^{[\mathrm{d}]}$ & & & & & & -3.5 & -2.0 & -0.5 & -0.1 \\
\hline
\end{tabular}

$661{ }^{[a]}$ Average annual rainfall erosivity accumulated by event rainfall erosivity from minute resolution data (MJ mm $\left.662 \mathrm{ha}^{-1} \mathrm{~h}^{-1} \mathrm{y}^{-1}\right)$

$663{ }^{[b]}$ Average annual rainfall erosivity accumulated by daily rainfall erosivity also from minute data $\left(\mathrm{MJ} \mathrm{mm} \mathrm{ha}^{-1} \mathrm{~h}^{-1}\right.$ $\left.664 \mathrm{y}^{-1}\right)$

$665{ }^{[c]}$ Relative deviation of $\mathrm{R}_{\text {daily }}$ from $\mathrm{R}_{\mathrm{event}}(\%)$; 
${ }^{\text {[d] }}$ The mean value of RDs for all 16 stations (\%).

667 
Table 3 The symmetric mean absolute percentage error, $\operatorname{MAPE}_{\mathrm{sym}}(\%)$, for the independent

669 data sets from the six validation stations at the four different temporal scales for Models I, II

670 and III

\begin{tabular}{|c|c|c|c|c|c|c|c|c|}
\hline & & & Yang & & & & & \\
\hline & & Tonghe & cheng & Xichang & Huangshi & Tengchong & Changting & Ave. \\
\hline \multirow{3}{*}{$\mathrm{R}_{\text {day }}$} & Model I & 66.6 & 80.2 & 72.4 & 69.6 & 61.0 & 58.1 & 68.0 \\
\hline & Model II & 65.4 & 78.9 & 69.7 & 63.9 & 59.1 & 57.2 & 65.7 \\
\hline & Model III & 37.3 & 41.3 & 43.7 & 40.9 & 35.4 & 35.2 & 39.0 \\
\hline \multirow{3}{*}{$\mathrm{R}_{\mathrm{ave} \text { _half }}$} & Model I & 39.2 & 30.9 & 37.0 & 33.0 & 30.7 & 22.0 & 32.1 \\
\hline & Model II & 33.2 & 26.5 & 24.5 & 22.8 & 22.2 & 24.0 & 25.5 \\
\hline & Model III & 16.9 & 11.3 & 28.6 & 17.3 & 15.1 & 12.2 & 16.9 \\
\hline \multirow{3}{*}{$\mathrm{R}_{\text {year }}$} & Model I & 22.5 & 29.9 & 23.1 & 19.4 & 19.3 & 17.1 & 21.9 \\
\hline & Model II & 22.2 & 29.0 & 21.3 & 20.2 & 15.4 & 22.6 & 21.8 \\
\hline & Model III & 10.3 & 12.0 & 17.6 & 7.4 & 9.6 & 7.6 & 10.7 \\
\hline \multirow{3}{*}{$\mathrm{R}_{\text {annual }}$} & Model I & 7.7 & 14.7 & 12.9 & 3.8 & 16.6 & 10.6 & 11.0 \\
\hline & Model II & 7.0 & 13.6 & 10.8 & 2.8 & 11.3 & 19.3 & 10.8 \\
\hline & Model III & 2.2 & 5.5 & 15.6 & 2.3 & 8.3 & 4.6 & 6.4 \\
\hline
\end{tabular}

671

672 
Table 4 The Nash-Sutcliffe model efficiency coefficient, ME, for the independent data

674 sets from the six validation stations at the four different temporal scales for Models I, II

675 and III.

\begin{tabular}{|c|c|c|c|c|c|c|c|c|}
\hline & & Tonghe & Yangcheng & Xichang & Huangshi & Tengchong & Changting & Ave. \\
\hline \multirow{3}{*}{$\mathrm{R}_{\text {day }}$} & Model I & 0.55 & 0.35 & 0.72 & 0.56 & 0.29 & 0.85 & 0.55 \\
\hline & Model II & 0.55 & 0.36 & 0.73 & 0.56 & 0.35 & 0.85 & 0.57 \\
\hline & Model III & 0.88 & 0.93 & 0.95 & 0.97 & 0.89 & 0.97 & 0.93 \\
\hline \multirow{3}{*}{$\mathrm{R}_{\mathrm{ave \_ half}}$} & Model I & 0.90 & 0.84 & 0.93 & 0.90 & 0.84 & 0.93 & 0.89 \\
\hline & Model II & 0.92 & 0.87 & 0.94 & 0.92 & 0.85 & 0.90 & 0.90 \\
\hline & Model III & 0.99 & 0.99 & 0.95 & 0.98 & 0.98 & 0.98 & 0.98 \\
\hline \multirow{3}{*}{$\mathrm{R}_{\text {year }}$} & Model I & 0.62 & 0.15 & 0.74 & 0.61 & 0.47 & 0.68 & 0.55 \\
\hline & Model II & 0.64 & 0.16 & 0.77 & 0.61 & 0.65 & 0.52 & 0.56 \\
\hline & Model III & 0.90 & 0.89 & 0.85 & 0.95 & 0.95 & 0.95 & 0.91 \\
\hline
\end{tabular}

676

677 
678 Figures

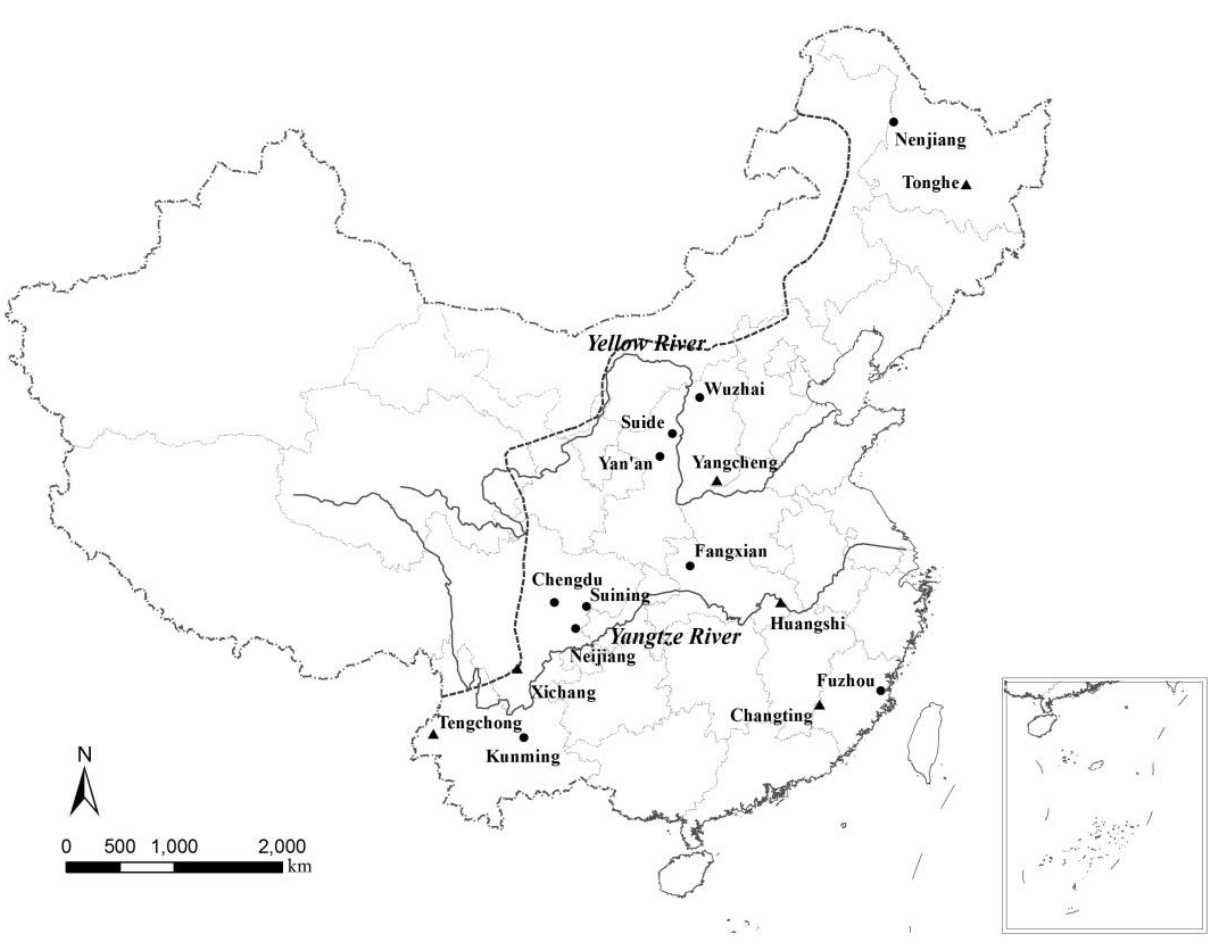

679

680 Fig. 1. Distribution of the 16 stations with one-minute resolution rainfall data in eastern

681 China. The eastern part of China, which is seperated by the short dashed line, experiences

682 mainly water erosion as opposed to wind erosion. Ten stations marked with dots were used to

683 derive the function between daily $\mathbf{E I}_{30}$ values and the corresponding daily rainfall indices.

684 The other six stations marked with triangles were used to assess the models.

685 


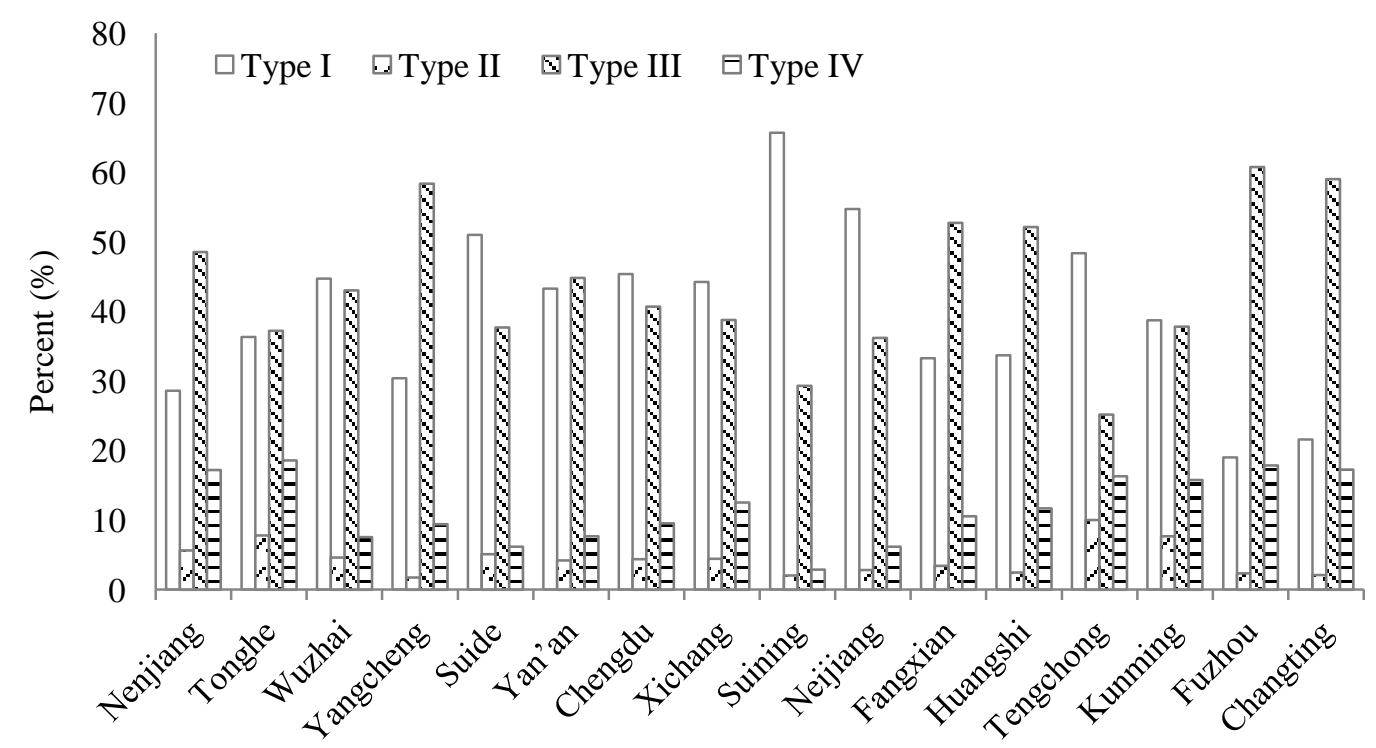

686

687

688

689

690

Fig. 2. Percent of the four types of relationships between daily rainfall and events. Type $I$ is when an event begins and finishes in the same day; Type II is when more than one complete rainfall event occurs in one day; Type III is when only a part of a rainfall event occurs in one day; and Type IV includes all remaining situations.

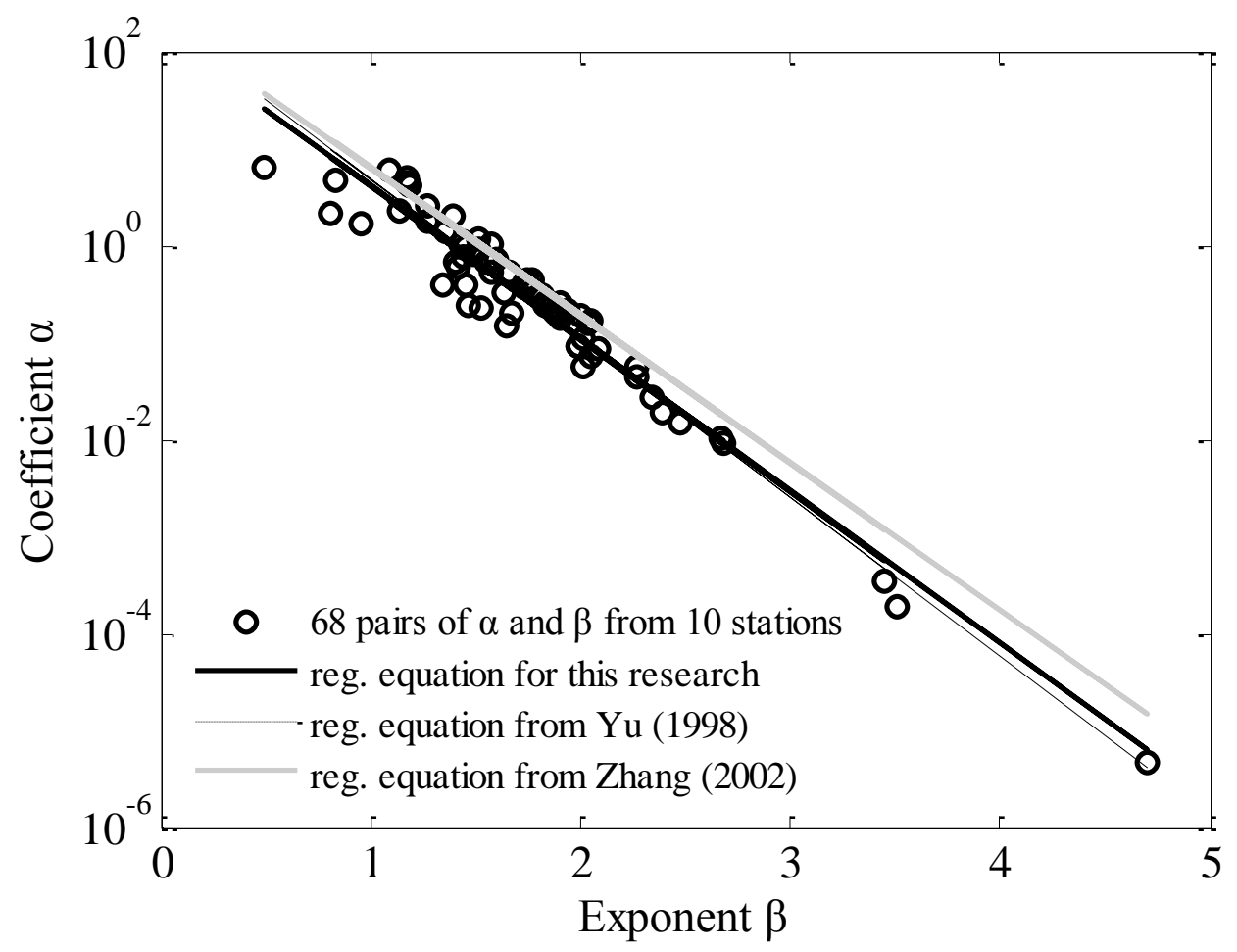

Fig. 3. Relationship between exponent $\beta$ and coefficient $\alpha$ in Model I (equation 11) for the 68 
(a) Rainfall for four northern stations

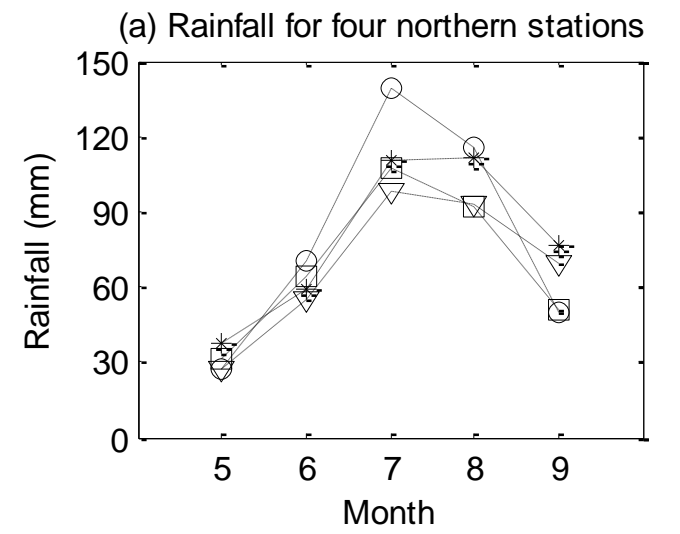

(c) Rainfall for six southern stations

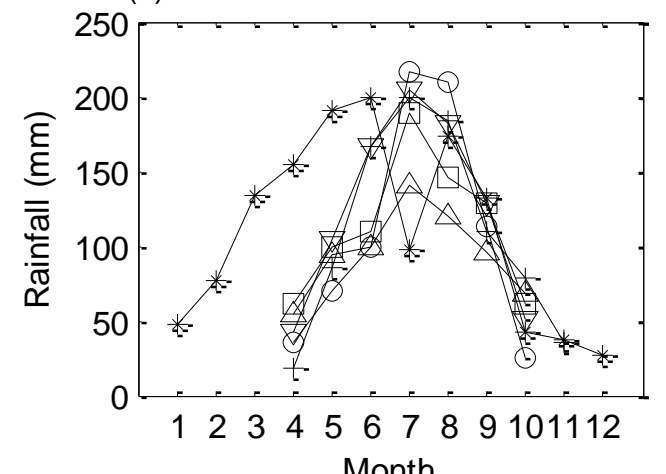

(b) $\alpha$ for four northern stations

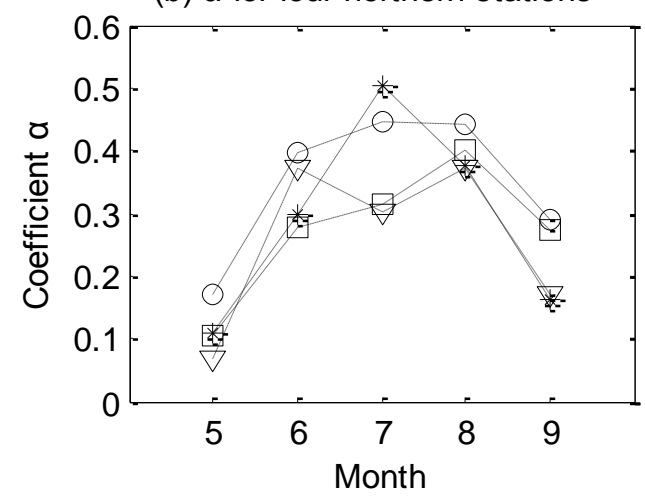

(d) $\alpha$ for six southern stations

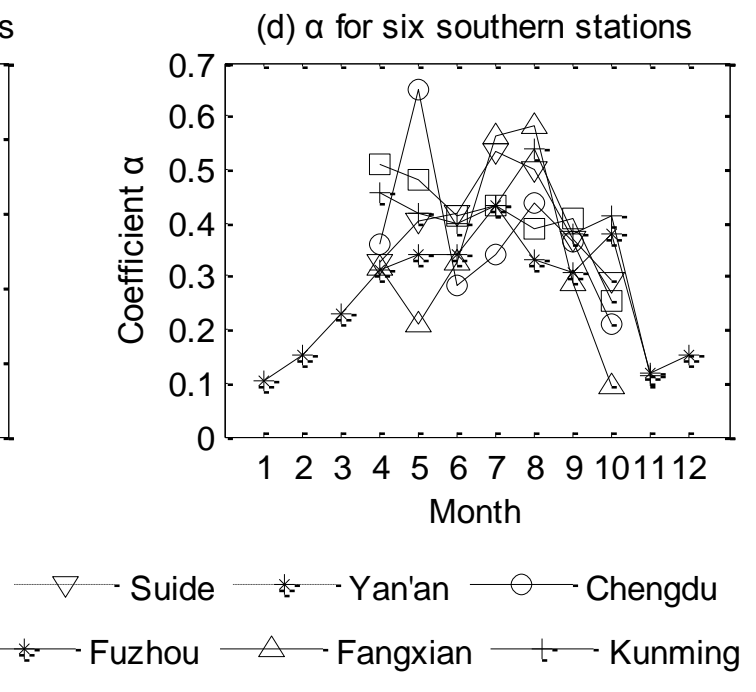

698

699

700

701

702

month/station combinations used from the ten calibration stations. The solid line shows equation 16, which is the best fit line from this research; the short dashed line shows equation 20, which represents the equation developed by Yu (1998) using data from Australia; and the long dashed line shows equation 22, which was fitted using the results from Zhang et al. (2002).

Fig. 4. Seasonal variations of rainfall for four northern stations (a) and six southern stations (c). Seasonal variations of coefficient $\alpha$ for four northern stations (b) and six southern stations (d). 


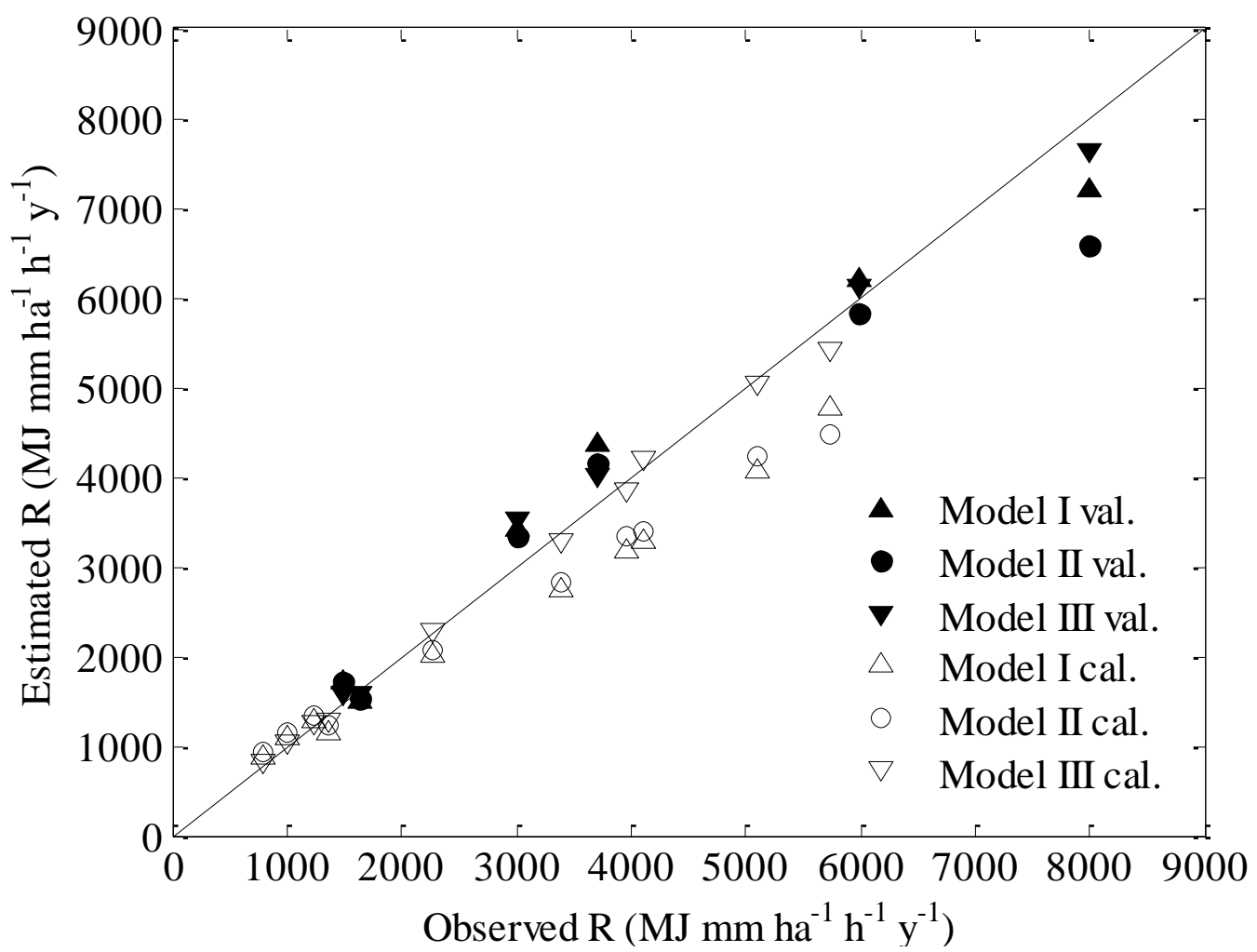

704 Fig. 5. Comparison of estimated R-factor values based on three models with observed values using one-minute resolution data. The solid dots represent six validation stations with parameters derived based on ten calibration stations. The open dots represent the ten calibration stations with parameters derived from six validation stations. 
(a) Cumulative half-month $\mathrm{R}$ for Tonghe station
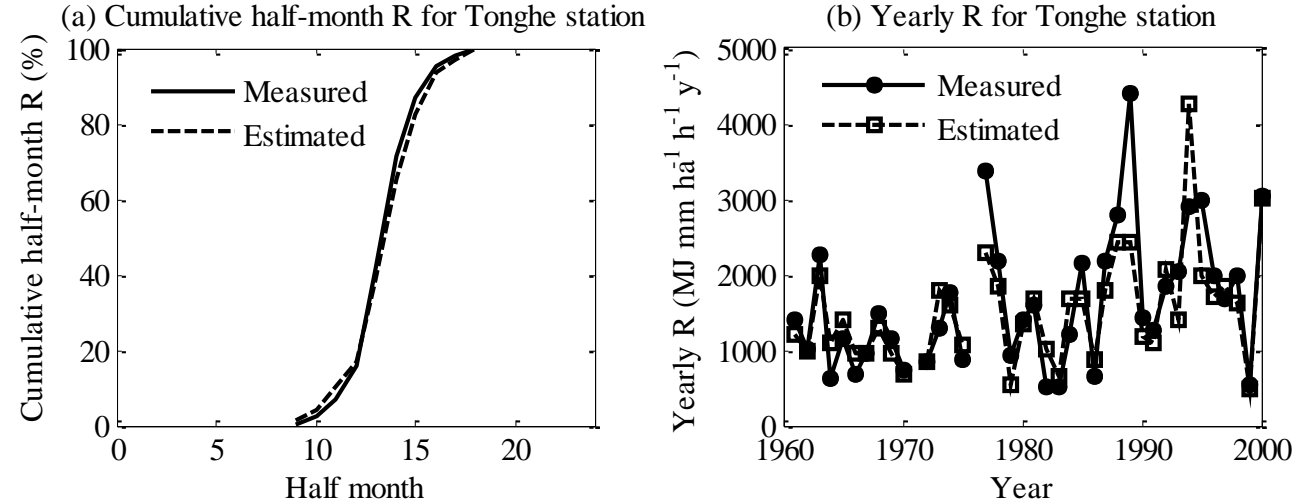

(c) Cumulative half-month $\mathrm{R}$ for Tengchong station

(d) Yearly R for Tengchong station
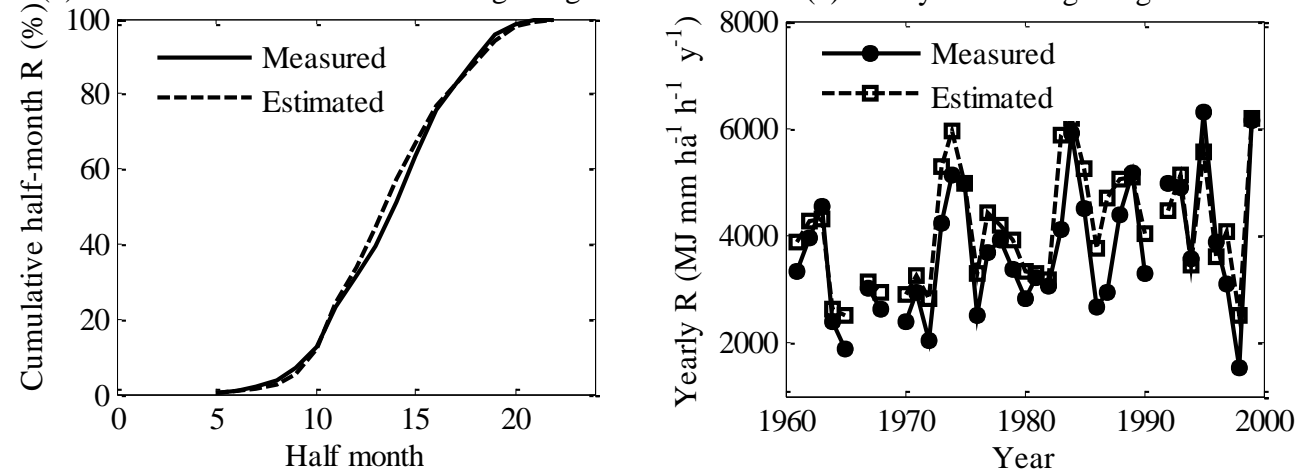

Fig. 6. Comparison of cumulative half-month R-factor values for the Tonghe station (a) and

711 Tengchong station (c); and yearly R-factor values for the Tonghe station (b) and the

712 Tengchong station (d) between observation values calculated using one-minute resolution rainfall data and estimated values using daily rainfall data by Model II. The years without marks were ineffective years and not use in the study. 
(a) Tonghe station with Model II

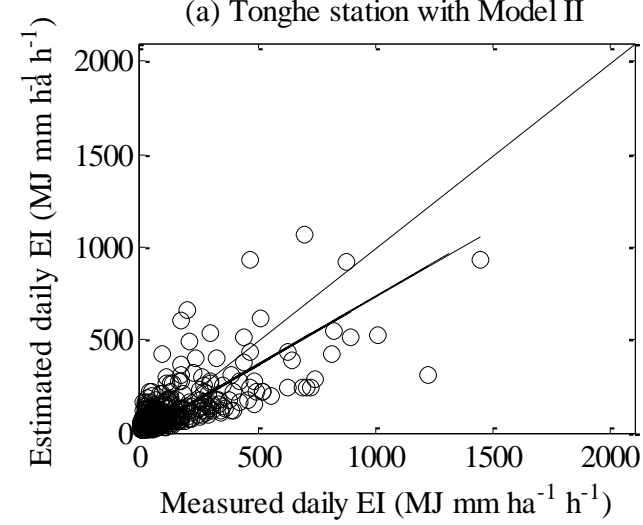

(c) Tonghe station with Model III

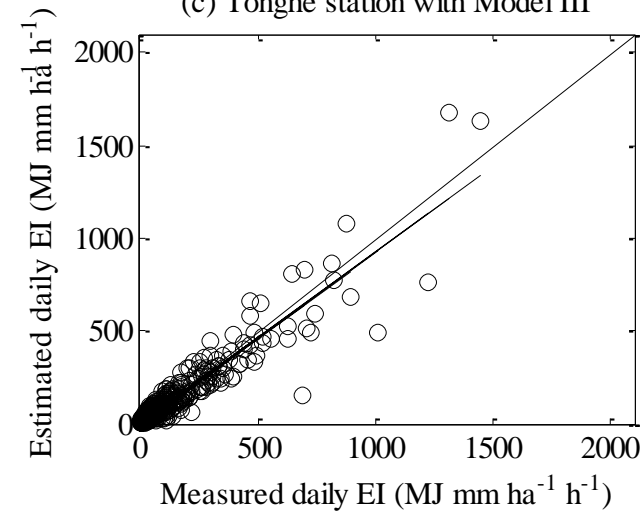

(b) Tengchong station with Model II

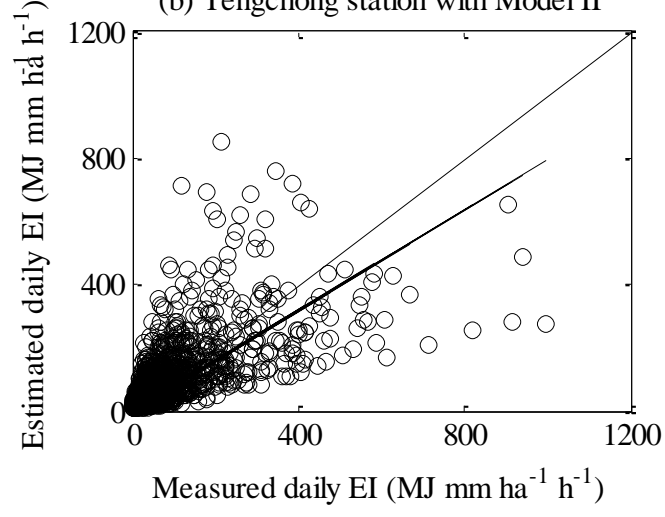

(d) Tengchong station with Model III

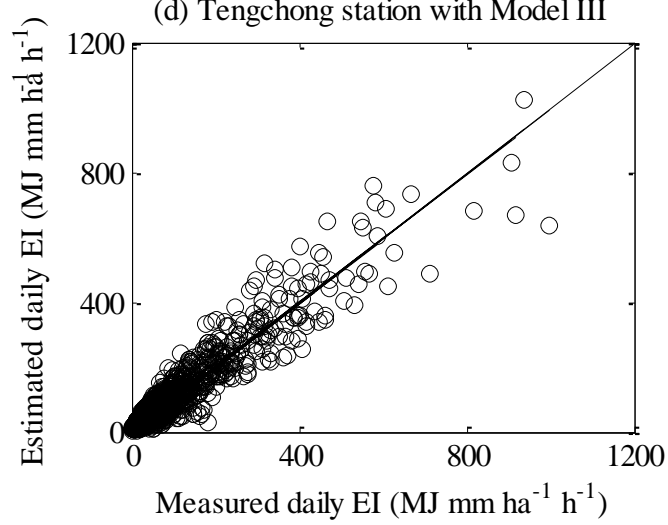

Fig. 7. Comparison of measured daily $\mathrm{EI}_{30}$ index with estimations using Model II for the

717 Tonghe station (a) and the Tengchong station (b), and by Model III for the Tonghe station (c) and the Tengchong station (d). The dashed line is the best linear fit line with intercept forced to zero. 


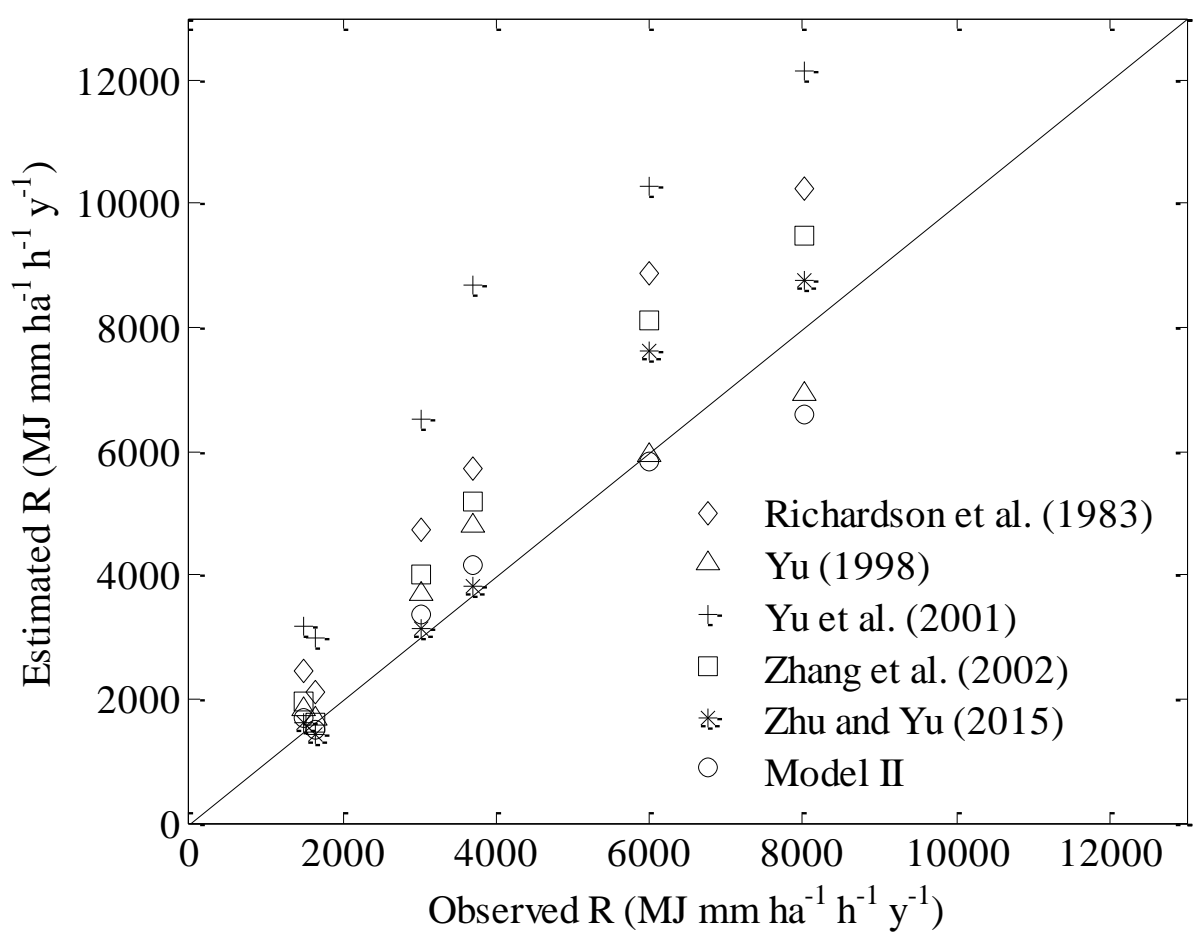

Fig. 8. Comparison of estimated annual average R-factor values calculated using daily rainfall amounts by five different models with that using one-minute resolution data for the six independent validation stations. The model parameter values used were: (1) $\beta=1.81$, $\alpha_{\text {warm_season }}=0.41$ and $\alpha_{\text {cool_season }}=0.18$ in Richardson et al. (1983); (2) $\alpha_{1}=0.79, \beta=1.49, \eta=0.29$ in Yu (1998); (3) $\alpha_{1}=2.03, \beta=1.40, \eta=0.19$ in Yu et al. (2001); (4) equations 21 and 23 in Zhang et al. (2002); (5) $\alpha_{1}=0.20, \beta=1.76, \eta=0.76$ when $R$ is lower than $6000 \mathrm{MJ} \mathrm{mm} \mathrm{ha} a^{-1} h^{-1} y^{-1}$ and $\alpha_{1}=0.68, \beta=1.58, \eta=0.38$ when $R$ is greater than $6000 \mathrm{MJ} \mathrm{mm} \mathrm{ha}{ }^{-1} h^{-1} y^{-1}$ in $\mathrm{Zhu}$ and $\mathrm{Yu}$ (2015); (6) Model II as parameterized in this study. 